Portland State University

PDXScholar

\title{
A multivariate test of evolutionary stasis in Homo sapiens
}

Jon Geoffrey Kleckner

Portland State University

Follow this and additional works at: https://pdxscholar.library.pdx.edu/open_access_etds

Part of the Biological and Physical Anthropology Commons, and the Evolution Commons Let us know how access to this document benefits you.

\section{Recommended Citation}

Kleckner, Jon Geoffrey, "A multivariate test of evolutionary stasis in Homo sapiens" (1989). Dissertations and Theses. Paper 3871.

https://doi.org/10.15760/etd.5755

This Thesis is brought to you for free and open access. It has been accepted for inclusion in Dissertations and Theses by an authorized administrator of PDXScholar. Please contact us if we can make this document more accessible: pdxscholar@pdx.edu. 
AN ABSTRACT OF THE THESIS OF Jon Geoffrey Kleckner for the Master of Arts in Anthropology presented May 10, 1989.

Title: A Multivariate Test of Evolutionary Stasis in Homo sapiens.

APPROVED BY MEMBERS OF THE THESIS COMMITTEE:

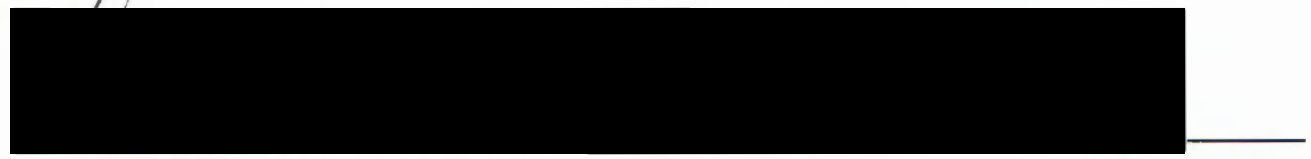

Marc R. Feldesman, Chairman

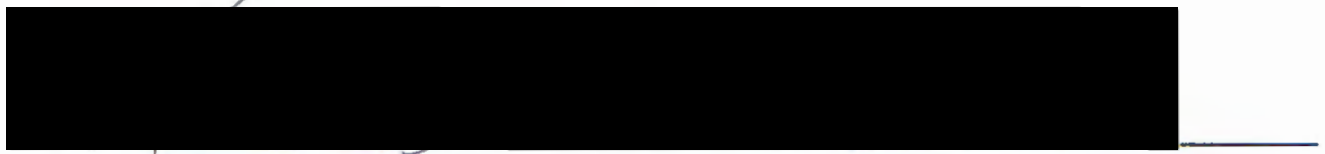

Kenneth M. Ames

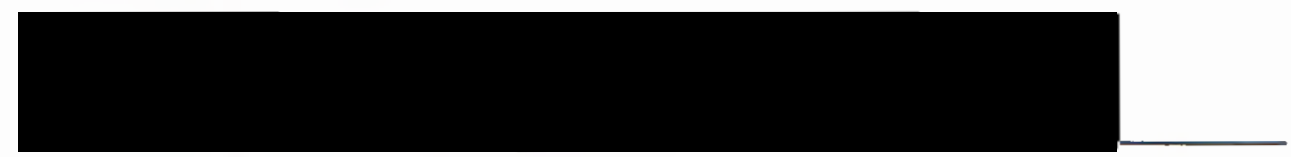

Patricia L. Kramer

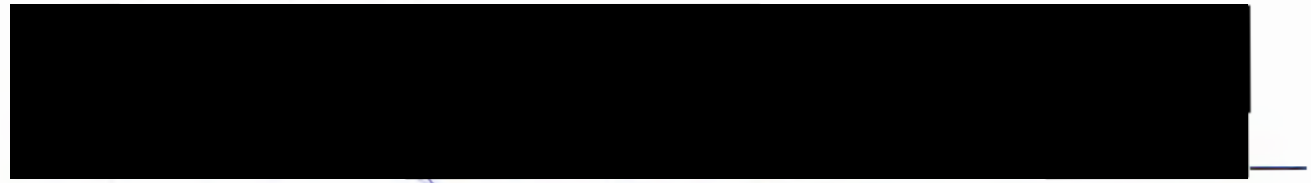

Nancy A. Perrin

In the past, efforts to prove or disprove stasis in hominids have relied upon univariate tests such as Students's t-test. Severe methodological and interpretive problems arise from the misapplication of univariate statistics to questions concerning variation in shape through time. These are questions best addressed using the multivariate approach of morphometrics. Eighteen cranial 
dimensions drawn from $33 \mathrm{mid}$ and late Pleistocene Homo sapiens were examined using principal component analysis (PCA). PCA divided the sample into two distinct morphologies. Archaic Homo sapiens of the mid Pleistocene clustered with Würm I neanderthals and apart from post Göttweig early anatomically modern Homo sapiens. ANOVA and Cluster analysis confirm the groups represent two different morphologies rather than a single spectrum of morphological change. These results support stasis rather than phyletic gradualism during this period of hominid evolution. 


\title{
A MULTIVARIATE TEST OF EVOLUTIONARY STASIS \\ IN Homo sajpiens
}

\author{
by \\ JON GEOFFREY KLECKNER
}

A thesis submitted in partial fulfillment of the requirements for the degree of

\begin{abstract}
MASTER OF ARTS
in

ANTHROPOLOGY
\end{abstract}

Portland State University

1989 


\section{TO THE OFFICE OF GRADUATE STUDIES:}

The members of the committee approve the thesis of Jon Geoffrey

Kleckner presenterd May 10, 1989.

Marc R. Feldesman, Chairman

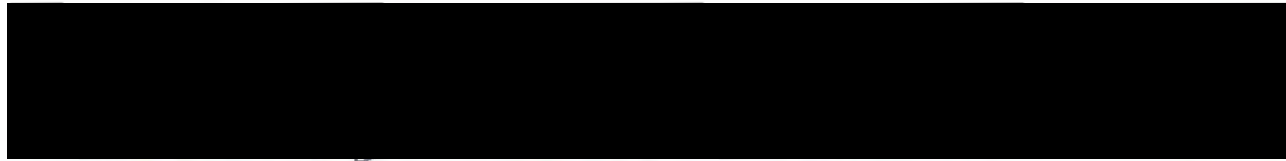

Kenneth M. Ames

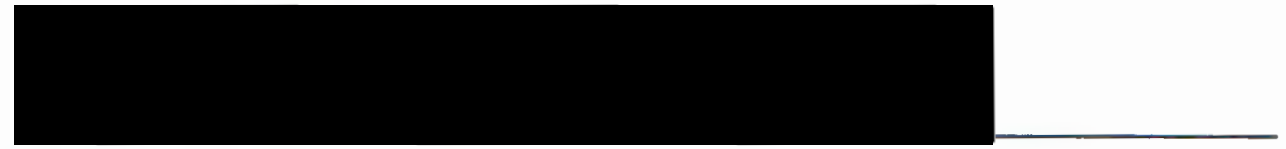

Patricia L. Kramer

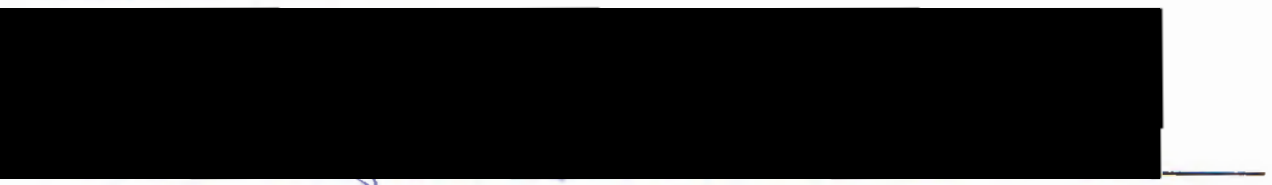

Nancy A. Perrin

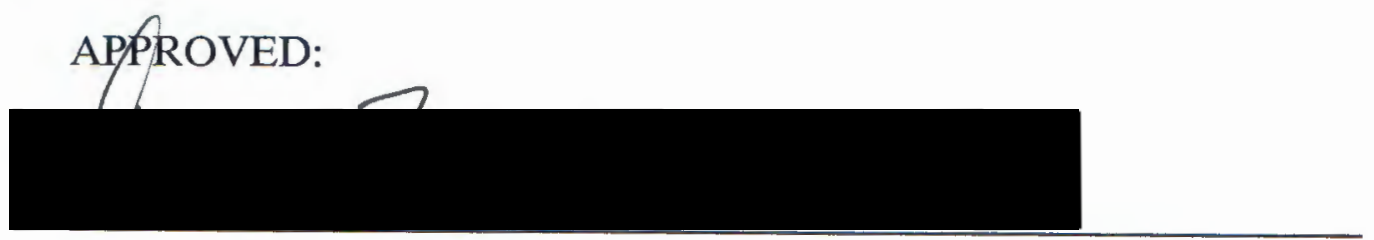

Marc R. Feldesman, Chair, Department of Anthropology

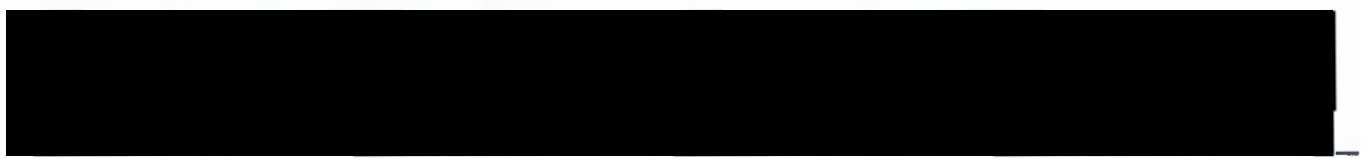

C. William Savery, Vice Provost for Graduate Studies and Research 


\section{ACKNOWLEDGMENTS}

Several people made substantial contributions to this thesis. First, I would like to thank Chris Stringer for providing me with his data and his advice. I would also like to thank my committee for all their helpful suggestions. Marc Feldesman was of especial assistance. As a friend, he far exceeded the duties of a committee chairman. Lastly, I must thank my wife. For the last three years she provided life saving support (though I think her patience may have been strained from time to time). 


\section{TABLE OF CONTENTS}

\section{PAGE}

ACKNOWLEDGEMENTS $\ldots \ldots \ldots \ldots \ldots \ldots \ldots \ldots$ iii

LIST OF TABLES $\ldots \ldots \ldots \ldots \ldots \ldots \ldots \ldots \ldots \ldots$ vi

LIST OF FIGURES $\ldots \ldots \ldots \ldots \ldots \ldots \ldots \ldots \ldots$ vii

\section{CHAPTER}

I INTRODUCTION $\ldots \ldots \ldots \ldots \ldots \ldots \ldots \ldots$

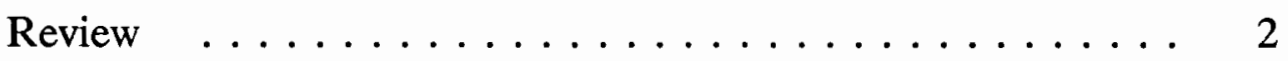

II MATERIALS AND RESEARCH METHODS $\ldots \ldots \ldots \ldots .7$

Specimens $\quad \ldots \ldots \ldots \ldots \ldots \ldots \ldots \ldots \ldots \ldots$

Chronological Framework

Dimensions $\ldots \ldots \ldots \ldots \ldots \ldots \ldots \ldots \ldots \ldots$

Measurements

Methods of Data Analysis $\ldots \ldots \ldots \ldots 21$

Principal Component Analysis

Interpreting Principal Component Analysis

Analysis

III RESULTS ......................... 29

Univariate Analysis $\ldots \ldots \ldots . \ldots . \ldots . \ldots 29$

Multivariate Analyses $\ldots \ldots \ldots \ldots \ldots \ldots$

Interpretation of Components 
CHAPTER

PAGE

IV DISCUSSION $\ldots \ldots \ldots \ldots \ldots \ldots \ldots \ldots \ldots \ldots$

Univariate Analysis $\ldots \ldots \ldots \ldots \ldots \ldots$

Principal Component Analysis $\ldots \ldots \ldots \ldots \ldots$

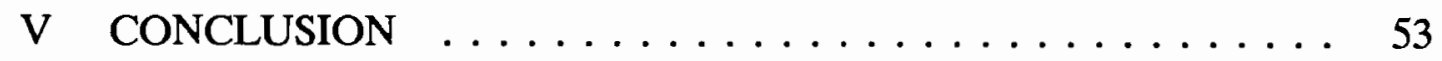

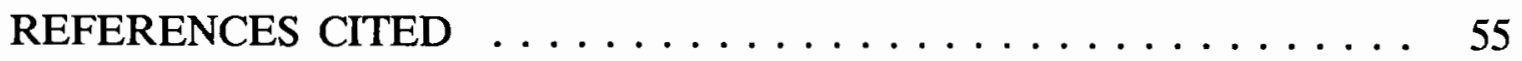




\section{LIST OF TABLES}

TABLE

PAGE

I Specimens by Temporal Group $\ldots \ldots \ldots \ldots 13$

II Measurements by Cranial Region $\ldots \ldots \ldots \ldots$

III Raw Data by Groups $\ldots \ldots \ldots \ldots 27$

IV Logged Data by Groups $\ldots \ldots \ldots \ldots \ldots \ldots$

V Mean and Standard Deviation of Logged Variables by

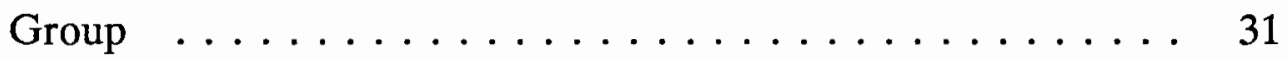

VI Significant Differences Between Groups $\ldots \ldots \ldots . \ldots 32$

VII Loadings and Variance for Components I $-\mathrm{V} \ldots \ldots$

VIII Rank Order of Component I Scores . . . . . . . . . . 39

IX Rank Order of Component II Scores . . . . . . . . . 40

X Rank Order of Component III Scores $\ldots \ldots \ldots \ldots 1$

XI Component Means \& Significant $(p \leq .05)$ Differences $\ldots . .42$ 


\section{LIST OF FIGURES}

FIGURE

PAGE

1. Cranial Diagram Illustrating Selected Landmarks and

Dimensions ........................ 19

2. Illustration of Chord, Subtense, and Fraction $\ldots \ldots 20$

3. Dendrogram Produced by an Unweighted Pairgroup Cluster

Analysis of Logged Measurements . . . . . . . . . . 36

4. Skree Plot of Component Loadings . . . . . . . . . . 37

5. Box Plot of Component I by Group $\ldots \ldots \ldots 43$

6. Box Plot of Component III by Group . . . . . . . . . 44

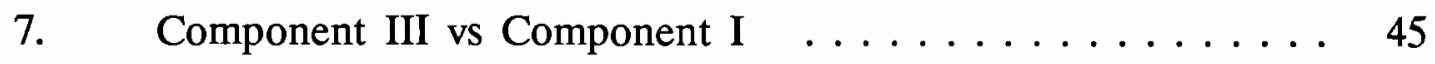

8. Dendrogram Produced by an Unweighted Pairgroup Cluster

Analysis of the First Three Component Scores $\ldots \ldots . . .46$

9. Component III vs Component I: Recent Europeans _... . 52 


\section{CHAPTER I}

\section{INTRODUCTION}

No topic in evolutionary biology is more important than variation. In fact, nearly every question asked by paleontologists or evolutionary biologists is reducible to a question of variability. This was not always the case. Before the modern evolutionary synthesis most research operated on typological assumptions. After the synthesis, however, research focused on explanations of variability within and among populations.

In the early 1970's, Eldredge and Gould (1972) presented a new view of evolution. Their model of punctuated equilibrium refocused interest on variability and, in particular, on temporal variation. Their view suggested the synthetic theory's gradualist model explained temporal variation too simplistically.

The synthetic theory's model of phyletic gradualism states that evolution occurs as the gradual transformation of an entire ancestral population (Eldredge and Gould; 1972). Morphological differences continuously accrue from the minute genetic differences that occur from one generation to the next. Eldredge and Gould (1972) proposed that evolution is not continuous and gradual as the modern synthesis suggests, but rather is characterized by stasis after rapid evolutionary change. They believe that stasis (a period of no 
evolutionary change) normally follows speciation. They argue that speciation is most often caused by the genetic isolation of peripheral populations (allopatric speciation). Eldredge and Gould (1972:94) suggest that "... selection always maintains an equilibrium between populations and their local environment..." after a rapid adjustment to new conditions. They pointed to the fossil record as evidence of punctuated equilibrium's validity and suggested that fossil data more commonly documented stasis than phyletic gradualism.

\section{REVIEW}

A fundamental premise of punctuated equilibrium is that most evolutionary change occurs during allopatric speciation while stasis dominates at all other times (Eldredge \& Gould 1972). Abrupt morphological breaks in the fossil record are used to demarcate the existence of new species. The central problem of punctuated equilibrium is to document stasis.

The literature is replete with attempts to prove or disprove that stasis occurs. The methods used are generally similar to one another. Their objectives are twofold: quantifying the amount of change and establishing the rate of change. In the past, unfortunately, problems emerged on both counts, and success in demonstrating punctuated equilibrium or phyletic gradualism has eluded researchers.

The problem of interpreting evolutionary rates is a theoretical problem. The issue revolves around the different implications of minor evolutionary change under the two models. 
Rightmire (1981, 1982, 1985, 1986), a proponent of punctuated equilibrium, attempted to measure the rate of change in Homo erectus. $\mathrm{He}$ regressed cranial capacity on time and obtained a slope with a $95 \%$ confidence interval that included zero. This led him to conclude the rate of change in cranial capacity was zero.

Levinton (1982) criticized Rightmire's sample size and technique. He noted that a 95\% confidence interval placed Rightmire's slope for biauricular breadth between -28.33 and 25.99 . Levinton believes an interval only establishes a margin of error and does not test for significant departure from zero. Strangely, Levinton suggested a slope of $0.00 \pm 0.0001$ could vary significantly from zero and still evidence gradual evolution.

Most advocates of punctuated equilibrium disagree with Levinton's extreme position. Stanley (1979), as well as Gould and Eldredge (1977) recognize that change through time is inevitable, but that microevolutionary changes produced by natural selection occur at a rate insufficient to cause speciation. Stanley found the proportional rate of intraspecific change in five hominid species too slow to produce the net change experienced by the entire lineage. He concluded that interspecific natural selection (species selection) must account for most of the change.

It is clear that a test of stasis must accommodate inevitable variation through time. Somewhere between Rightmire's liberal interpretation of confidence intervals and Levinton's assertion of gradual change in a slope of $0.00 \pm 0.0001$ must lie the best answer. 
Recently, Bookstein (1987) suggested that solution must also consider the implications of random variation. He emphasized that stasis and gradualism represent different rates of evolutionary change. Bookstein believes random variation constitutes the absence of any rate of change. He thinks that before gradual change or stasis is proven, random variation through time (random walk) must be ruled out.

While theoretical problems complicate the interpretation of evolutionary rates, the problem of quantifying change is primarily methodological. The traditional use of univariate techniques is particularly troublesome.

Wolpoff (1984), for example, used Student's t-test and was able to show significant differences in cranial-dental measurements between early and late sub-populations of Homo erectus. Rightmire (1986) reanalyzed the data using Wolpoff's technique, but excluded two taxonomically questionable specimens. His results contradicted Wolpoff's and showed no significant difference in cranial capacity between early and late Homo erectus.

In response to Rightmire, Wolpoff (1986) applied his technique again to a different set of traits. In this analysis he considered the traits together, not independently as they had been in the past. When considered together, the traits again demonstrated significant change.

Two implications emerge from Wolpoff's work. The first concerns the inconsistency of univariate tests as a means of quantifying evolutionary change. The exchange between Wolpoff and Rightmire shows that the selection of univariate metrics clearly influences a test's outcome. The results of a test 
using one dimension can contradict the results of another test using a different dimension. The researcher is left wondering which measurement, if either, best measures evolutionary change'.

The problem arises because univariate tests only measures differences in the distance between two landmarks. Evolutionary change, however, may involve considerably more than differences in size.

Gould (1982) noted that questions of temporal variation address change in form. Few have disagreed with his position. Frayer (1984), Wolpoff et al (1984), and Oxnard (1984) each argued that change in shape is at issue in tests of evolutionary transformation. They also contend a univariate test only describes size. While size is not irrelevant, to focus on it alone ignores shape (Frayer 1984).

Wolpoff's multivariate approach departed from past efforts to quantify evolutionary change. Though using only a few variables, his analysis attempted to address change in shape, rather than just change in size, in temporal subsamples of Homo erectus.

Another, more subtle, implication emerged from Wolpoff's use of subsamples in that analysis. He recognized the problem of organizing coarsely dated fossils within a fine serial chronology. Instead, he adopted a broad chronology befitting a roughly dated sample. Wolpoff compared the variance in each subpopulation to reach a conclusion of gradual change. His method

${ }^{1}$ This problem is replicated in taxonomy. Consider the different solutions offered by phenetics and evolutionary taxonomy. 
accommodated minor population variation without imposing the rigid standard of gradualism advocated by Levinton.

These previous efforts to prove or disprove stasis, as well as the theoretical development of punctuated equilibrium suggest a number of strategies required to address evolutionary tempo. The first is a biologically realistic definition of stasis. In this context, stasis is defined as no change in the morphological (size and shape) variability characteristic of a population. In practical terms, this means that a population's morphological variability will not randomly fluctuate or gradually shift over time, but rather remain constant throughout a populations life.

As suggested above, morphological variability is unmeasurable using a univariate test of individuals organized in a fine chronological sequence. It is, instead, best addressed in a multivariate test of a population's variation.

This study will adopt the methodology suggested by previous work. I will use a multivariate test of cranial variation in Homo sapiens. To improve on Wolpoff's example, rather than use a limited number of dimensions, I will use a system of measurements designed to capture total cranial form.

I will compare temporal subsets of Homo sapiens to determine if sample variability changes or remains the same over time. If the variability changes by grade from one subset to the next, gradual change is indicated. If, instead, the variability remains the same between subsets, stasis is indicated. Alternatively, random variation is suggested by unpatterned differences between temporal subsets. 


\section{CHAPTER II}

\section{MATERIALS AND RESEARCH METHODS}

A statistical analysis of biological material must address not only the distributional properties of the population, but also the biological and evolutionary questions that first provoked the investigation. Here an important biological question concerns variation in shape through time. Shape is a geometric property and thus, untestable using univariate methods. As Pimentel suggests, shape analysis requires the multivariate approach of morphometrics. He defines morphometrics as "multivariate analysis that unravels the patterns of variation describing the form of a phenomenon..." (1979:1).

Equally important is the question of how variation is distributed through time. An analysis attempting to answer that question must clarify the differences resulting from temporal variation. The assumption of multiple populations in a test such as discriminant analysis is limiting in this regard. By describing the distance between two groups, discriminant analysis does not determine if distinct populations derived suddenly or, alternatively, if they represent segments along a spectrum of continuous variation.

A question of temporal variation requires an analysis of diversity within a single population. The question considers whether populations evolve gradually or experience stasis. That means only variation during a population's 
life is relevant. Too often, however, data indicating directional change in successional species are offered as evidence of phyletic gradualism (see Cronin et al 1981; Gingerich 1976). These data serve only to obscure the real object of inquiry: the nature of temporal variation within each population. It is, therefore, necessary to clearly define a population and test for temporal variation only within that population.

\section{SPECIMENS}

To test the morphological variation in mid and late Pleistocene Homo, I used data generously supplied by Dr. Chris Stringer of the British Museum. This data set includes 61 individuals represented by 66 measurements. These individuals include 33 specimens that Stringer labeled early anatomically modern, 13 Neanderthal, and 15 mid Pleistocene or archaic Homo sapiens.

Not every specimen, however, was complete enough to use. The face, for example, an important component of human evolution, rarely preserves. When I did a preliminary analysis that excluded facial measurements, I was unable to make sense of the outcome. Unfortunately, including those measurements meant eliminating 28 of 61 specimens from the original data set.

The earliest members of my original sample were particularly hard hit; only nine remained. This is arguably a minimal sample, but it includes virtually every early Homo sapiens complete enough for an analysis of cranial shape. Sample size is a long-standing problem for paleo-anthropologists. In this case the problem is unresolvable. 


\section{Chronological Framework}

To test morphological variation through time, the sample population must be organized into either temporal or taxonomic (morphological) subsets. Morphological criteria cannot be used to test for the evidence of morphological groups. Temporal criteria are more objective since subsets are not organized around a predetermined morphology.

Unfortunately, precisely dating mid and late Pleistocene Homo remains a problem. The critical transition from early Homo sapiens to anatomically modern Homo sapiens (AMHS) occurs outside the range of any generally accepted radiometric dating technique. While many AMHS are securely dated with carbon 14, most early Homo sapiens are placed in a glacial chronology based on palynological, faunal, and sometimes archaeological evidence.

Dates for most Neanderthal specimens are particularly crude. Many, especially those of Western Europe, depend only on a broad glacial chronology. Some authors report more precise dates linking Western European fossils to specific cold phases of the Würm I or Würm II stadia (see Day 1986). The faunal and palynological analyses supporting these dates, however, are not that precise and fail to accurately subdivide glacial stadia (Gamble 1986).

Some fossils, such as Forbes Quarry, lack temporal context altogether. Similarly, the Kabwe and Petralona crania derive from uncertain context. Dates for Petralona, for example, range from the Würm (Day 1986) to as early as 400 KYR (Murrill 1981). The best estimates of these fossils' age rely on a combination of morphological and archaeological evidence; techniques which 
are uncertain at best and decidedly circular in questions of evolution that are temporally dependent.

Recent attempts to apply techniques such as thermoluminescence (TL) to Würm age fossils are promising and may dramatically affect evolutionary schemes (see Valladas et al 1988). Unfortunately even these dates must be accepted with caution. Butzer (1982) reports a substantial margin of error in the more common application of $\mathrm{TL}$ on archaeological materials.

The rough dating applied to many early sample members constrained the chronological framework for the entire sample. Without greater dating precision it was impossible to arrange the sample members sequentially. Instead they had to be sorted into glacial periods.

The Riss-Würm interglacial (R/W) and Göttweig interstadial are reasonably well dated (see Gamble 1986, table 3.7). They were used to divide the Pleistocene into three stages: 1) the Middle Pleistocene prior to the Würm glaciation, 2) Würm I, and 3) Post Göttweig interstadial. Gamble dates the $\mathrm{R} / \mathrm{W}$ from $128 \mathrm{KYA}$ to $118 \mathrm{KYA}$. He dates the Würm I stadial between 118 KYA and 34 KYA. The Würm II stadial followed the Göttweig interstadial after 28 KYA.

It was possible to sort the sample into these stages with little difficulty. Table I presents the sample organization as well as the sources used to assign group membership. I used Mann and Trinkaus (1973) as the primary source for the early specimens. Day (1986) and Wolpoff (1980) provided dates for the later specimens. 
Only a few individuals were too insecurely or controversially dated to fit easily into these broad stages. The troublesome specimens were Forbes Quarry, Kabwe, Petralona, and Amud.

The problem of dating Forbes Quarry has no satisfactory solution. The fossil was removed from its faunal and geological context without analysis. With the context subsequently destroyed in quarrying, the fossil cannot be dated. Consensus, based on anatomical criteria, would place Forbes Quarry along with the classic Neanderthals in my second stage. While anatomical criteria are not ideal in this test, I placed Forbes Quarry tentatively in the Würm I stage to avoid dropping one of the few specimens available for analysis.

As noted above, Kabwe and Petralona derive from uncertain provenience. On the basis of faunal evidence thought to associate with the hominid material, Vrba reported a Middle Pleistocene date for Kabwe (Day 1986 from Vrba 1982). Though the argument for mid Pleistocene antiquity is weak, I prefer to accept it rather than omit an important specimen.

A similar argument is made in support of Middle Pleistocene antiquity for Petralona. Unfortunately estimates of Petralona's age are incredibly diverse. It was possible, however, to narrow the dating range to conform with the chronological framework used in this test. Few accept Poulianos' estimate of an early Würm age for Petralona (Day 1986). On the basis of Uranium series and faunal analysis, Cook et al (1982) and Murrill (1981) agreed that Petralona is no younger than the Riss glaciation. That placed Petralona safely 
in the Middle Pleistocene for this investigation.

Amud, like Petralona, is subject to disagreement. Chinzei (1970)

reported radiometric dates ranging from $5710 \pm 80$ to $28 \mathrm{KYA} \pm 9800$.

Faunal, archaeological, and geomorphological evidence, however, supports a Göttweig date for Amud. The great variability surrounding the radiometric dates undermines confidence in their accuracy. For this analysis I, like Chinzei, accept the Göttweig rather than the post Göttweig date for Amud. 
TABLE I

SPECIMENS BY TEMPORAL GROUP

Middle Pleistocene Homo sapiens

\section{SOURCE}

Jebel Irhoud 1

Kabwe

Petralona

Steinheim

Würm I \& Göttweig Homo sapiens

Amud

Forbes Quarry

La Chapelle

La Ferrassie

Monte Circeo 1
Mann \& Trinkaus (1973)

Vrba (1982)

Mann \& Trinkaus (1973)

Mann \& Trinkaus (1973)

Post Göttweig Homo sapiens

Abri Pataud

Afalou 9

Afalou 29

Afalou 32

Brno 3

Arena Candide

Arena Candide 1

Arena Candide 5

Chancelade

Cohuna

Cro Magnon 1

Cro Magnon 2

Dolni Vestonici 3

Kostenki 14

Mladec 1

Oberkassel (Female)

Predmost 3

Predmost 4

Qafzeh 6

Qafzeh 9

Skhul 5

Taforalt 11

Taforalt 17

Upper Cave 101
Suzuki \& Takai (1970)

Stringer et al (1984)

Mann \& Trinkaus (1973)

Mann \& Trinkaus (1973)

Mann \& Trinkaus (1973)

Stringer et al (1984)

Wolpoff (1980)

Wolpoff (1980)

Wolpoff (1980)

Wolpoff (1980)

Wolpoff (1980)

Wolpoff (1980)

Wolpoff (1980)

Wolpoff (1980)

Wolpoff (1980)

Day (1986)

Day (1986)

Wolpoff (1980)

Wolpoff (1980)

Wolpoff (1980)

Wolpoff (1980)

Wolpoff (1980)

Wolpoff (1980)

Mann \& Trinkaus (1973)

Mann \& Trinkaus (1973)

Mann \& Trinkaus (1973)

Wolpoff (1980)

Wolpoff (1980)

Wolpoff (1980) 


\section{DIMENSIONS}

I used a system of measurements originally defined in Howells (1973) study of modern human cranial variation. Howells developed a widely used system designed to capture cranial shape in a multivariate analysis.

Howells defined 57 cranial-facial dimensions developed to describe cranial form. Among these dimensions are radii extending from a point midway on the transmeatal axis, to ten cranial landmarks. This analysis uses an additional radius devised by Stringer to measure the occiput more thoroughly. The radii augment traditional lengths, breadths, arcs, and chords to reflect cranial shape more completely, especially in the sagittal plane.

Unfortunately, not all of Howells' measurements were of use in this analysis. Fossil remains rarely include intact bones and crania, yet most multivariate tests are not robust to missing data. When missing values occur, researchers usually drop either the variable or the specimen. I selected a set of measurements with the goal of balancing two contradictory objectives: adequately describe the cranium, and still retain the older, less complete specimens for analysis.

To meet that objective, I dropped 32 of the original variables, which were recorded on only a few specimens. A correlation analysis was performed on the remaining measurements to identify redundancy. Variables that correlated highly with several others were dropped. When a high correlation appeared among variables, I took care not to drop a measurement if an entire cranial region was eliminated from analysis. As a result of the correlation 
procedure, I dropped ten additional measurements.

I dropped an additional measurement due to uncertainty over an

estimated value for one specimen. Rather than drop the specimen, one of the few early Homo sapiens in the sample, I elected to drop the variable in question $^{2}$.

The eighteen measurements retained for analysis are summarized in Table II and described below (see Figures 1 and 2 for clarification of these metrics). Seven measure attributes of the face or upper face and eleven primarily measure the calvarium. Unfortunately, it was impossible to retain measurements of the basicranium. This part of the cranium was not often preserved in the oldest members of my sample.

$\underline{\text { Measurements }}^{3}$

Glabello-Occipital Length (GOL). This is the maximum cranial length measured from glabella to the occipital's most distant point on the sagittal plane.

Maximum Cranial Breadth ( $\mathrm{XCB}$ ). $\mathrm{XCB}$ is the maximum cranial

2 Stringer's original data gave 9mm for Steinheim's Nasio-Frontal Subtense (NAS). NAS is loosely tied to supraorbital projection and $9 \mathrm{~mm}$ seems too small even when compared to female anatomically modern Homo sapiens who lack measurable brow ridges. Regression based estimates of Steinheim's NAS ranged from $14 \mathrm{~mm}$ to $22 \mathrm{~mm}$ depending on reference population. Even with substantial assistance from Dr. Stringer this problem was not resolved. $\mathrm{He}$ indicated uncertainty about Steinheim's reconstruction around the nasion. Stringer remeasured the British Museum's cast twice and obtained noticeably different results on each occasion. At his suggestion, NAS was dropped to prevent unnecessary error from entering my analysis (see also Stringer 1974:319-320).

3 Measurement descriptions in this section closely follow Howells (1973). 
breadth perpendicular to the sagittal plane found at a point above the supramastoid crest.

Biasterionic Breadth (ASB). The asterion is the point at which the temporal, parietal, and occipital bones meet. ASB measures the distance between the right and left asterion.

Nasion-Bregma Chord (FRC). FRC is the frontal chord measured in the sagittal plane from the meeting point of the nasal and frontal bones (nasion) to the point at which the frontal and parietal bones meet (bregma).

Nasion-Bregma Subtense (FRS). FRS is the subtense of the frontal chord. It measures the distance from the chord to the highest point of convexity on the frontal bone in the sagittal plane.

Nasion-Bregma Fraction (FRF). FRF is the distance from nasion along the frontal chord at which FRS falls. Like FRC, FRF is quite variable and most useful with FRS and FRC as a measure of frontal bone shape.

Bregma-Lambda Chord (PAC). PAC is the parietal chord measured from bregma to the point where the occipital meets both parietal bones (lambda).

Bregma-Lambda Subtense (PAS). PAS is the distance from PAC to the highest point of convexity in the sagittal plane.

Bregma-Lambda Fraction (PAF). PAF is the distance from bregma along the parietal chord to the point where PAS falls.

Vertex Radius (VRR). VRR is measured from the mid point on the transmeatal axis to the highest point on the calvarium. 
Lambda Radius (LAR). LAR is also measured from the mid point of the transmeatal axis. It is the distance from the mid point to lambda and measures the rearward extension of the calvarium.

Nasal Height (NLH). NLH is the average distance measured on both sides of the cranium from nasion to the lowest point on the nasal aperture. NLH primarily measures mid facial height, but also indirectly measures the vertical dimension of the nasal aperture.

Orbital Height ( $\mathrm{OBH})$. Orbital height is measured perpendicular to the long axis of the orbit.

Supra-orbital Projection (SOS). SOS is measured from glabella to a point anterior to the most forward extension of the temporal line. Howells (1973) notes this is not only a measure of supra-orbital projection, but also of the frontal bone's lateral curvature.

External Palate Breadth (MAB). MAB is the maximum breadth between alveolar borders.

Cheek Height (WMH). WMH is the minimum distance from the orbit's lower border to the lower margin of the zygomatic process mesial to the masseter attachment. WMH varies with the degree of maxillary inflation.

Prosthion Radius (PRR). PRR is the distance from the mid point of the transmeatal axis to the mid line of the alveolar border.

Ectoconchion Radius (EKR). Ectoconchion is the intersection of the most anterior point of the orbit's lateral border and the orbit's long axis. EKR is the perpendicular distance from ectoconchion to the transmeatal axis. 
TABLE II

CALVARIUM

GOL Glabello-occipital Length

ASB Biasterionic Breadth

FRS Nasion-Bregma Subtense

PAC Bregma-Lambda Chord

PAF Bregma-Lambda Fraction

LAR Lambda Radius
XCB Maximum Cranial Breadth

FRC Nasion-Bregma Chord

FRF Nasion-Bregma Fraction

PAS Bregma-Lambda Subtense

VRR Vertex Radius

UPPER FACE

NLH Nasal Height

SOS Supraorbital Projection
OBH Orbital Height

EKR Echtoconchion Radius

FACE

MAB Palatal Breadth

PRR Prosthion Radius

WMH Cheek Height 

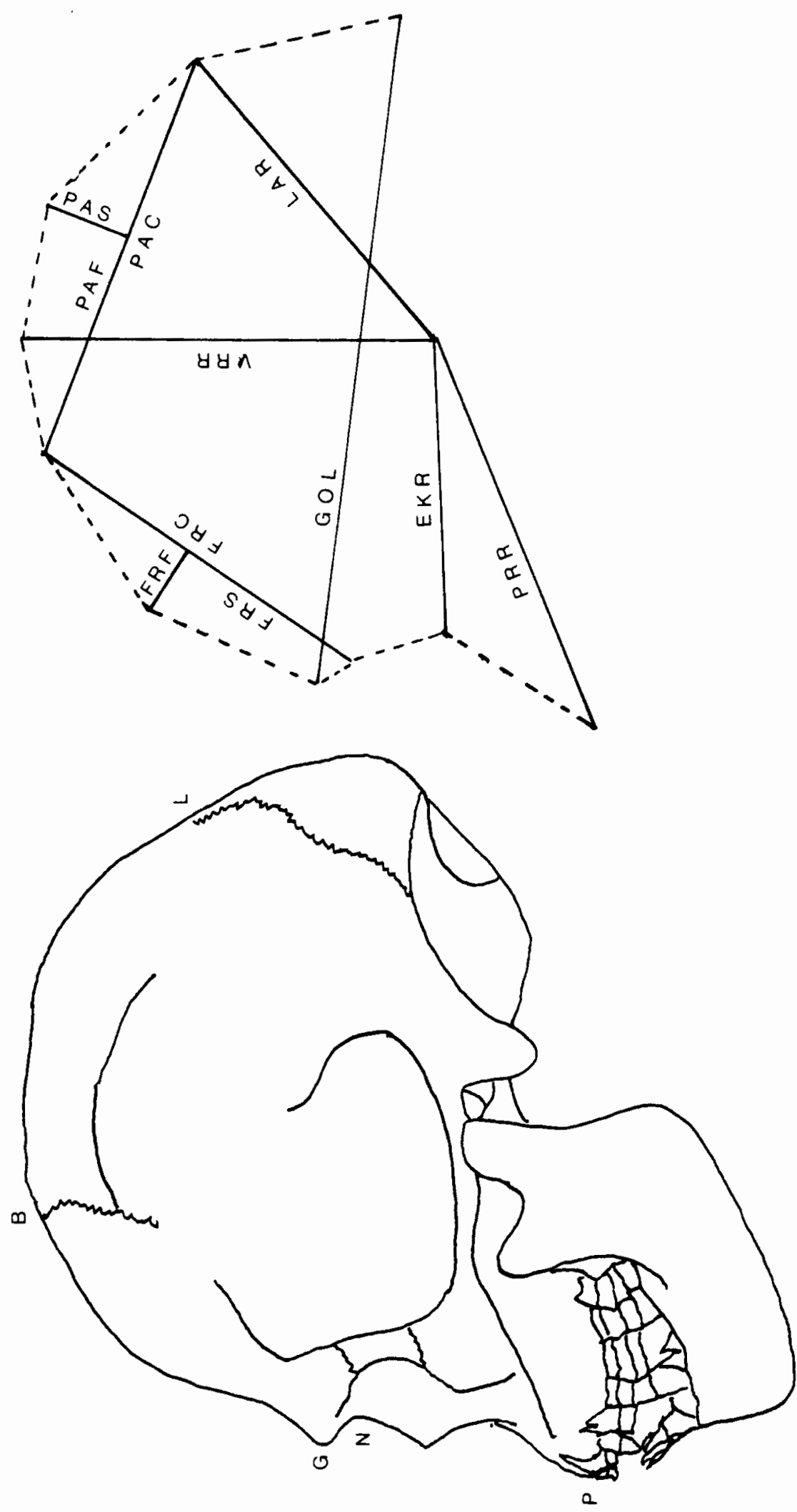

莺

열 


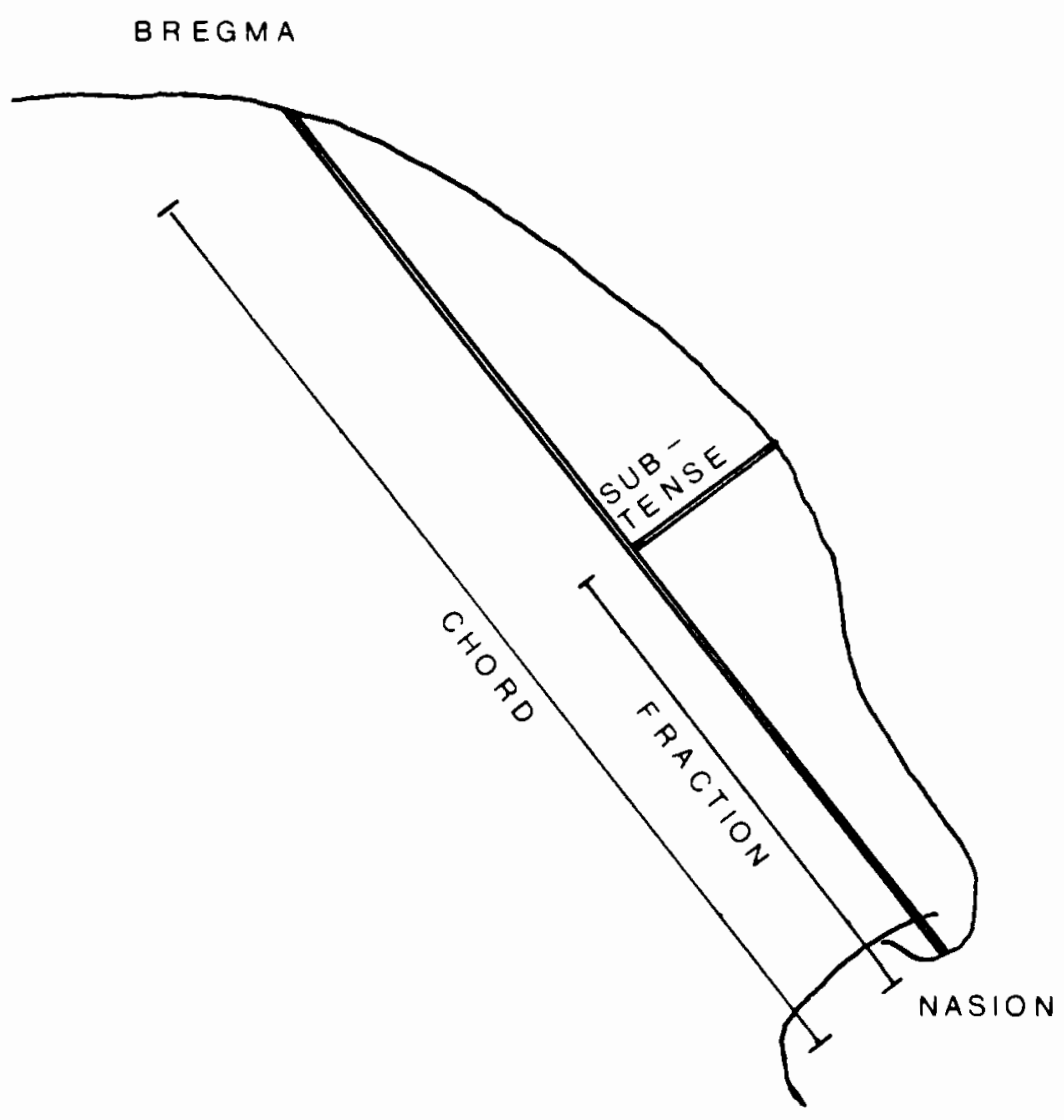

Figure 2. Illustration of chord, subtense, and fraction. 


\section{METHODS OF DATA ANALYSIS}

As patterns of variation in shape become complex, univariate analyses become decreasingly effective. As the results will show, univariate analyses can provide contradictory results linking different groups according to the metric used. The problem occurs because a single measure between two points (or of volume as in cranial capacity) is at best a measure of variation in size and not shape (Oxnard 1973).

Conversely, multivariate analysis simultaneously considers every measurement and provides a composite score for each individual (Feldesman 1976). The relationship among individual scores more clearly reflects variation both in shape and size of specimens within a sample.

\section{Principal Component Analysis}

Morphometricians use a number of techniques to address questions of variation including principal component analysis (PCA) and discriminant analysis. I selected PCA for this analysis because, unlike discriminant analysis, PCA makes no a priori assumptions regarding the data matrix structure or group membership (Morrison 1967). Clusters of individual composite scores in PCA originate from patterns of variation within the sample data rather than from the model imposed by the statistical technique.

PCA determines composite scores on a series of latent variables derived from either a correlation or variance-covariance matrix created from the original variables. The results of PCA performed on these two matrices are 
different and not comparable (Morrison 1967). A correlation matrix is used only when the original variables are measured on different scales.

The covariance matrix is preferred for several reasons.

(1) the analysis may be carried out in the original ... character space, leading to a direct interpretation of character loadings on components and a direct comparison between populations; (2) because the $i^{t h}$ principal component is defined as that linear combination of variables that accounts for the $i^{\text {th }}$ largest portion of the total character variance, maximization of the total in standardized data may give undue weight to less variable, relatively less precise measurements; and (3) the sampling theory for eigenvalues and eigenvectors computed from correlation matrices is exceedingly more complex than that for the covariance matrices (Bookstein et al 1985:26 from Anderson 1963).

Bookstein et al (1985) recommend the covariance matrix for PCA and suggest logarithmic transformation for heteroscedastic data, provided they are represented in common units of measurement.

Bookstein et al make several additional arguments in favor of the log transformation. They note that one of the primary assets of the general factor model (including PCA) is the ability to test the relationship of size and shape. Bookstein et al believe that a test of shape dependent on size (allometry) requires log transformed data to conform with a null hypothesis of isometry.

Log transformed variables are independent of their original scale and magnitude. In the case of isometry, $\log$ transformed variables maintain equal response to an underlying factor of size. Inequality implies an allometric relationship between size and shape. 
Bookstein et al also point out that logarithms transform nonlinear variables into linear variables. Commenting on the common absence of linearity in biological data, Bookstein et al (1985:25 from Smith 1980) report that "In the biophysical laws which regulate biological shape, lengths appear more often in products or powers than in sums...".

PCA extracts axes of variation from the variance-covariance matrix produced by the log transformed variables. The first extracted axis is the principal axis of variance in $n$ dimensional space (space defined by $n$ original variables). In an analogy to least squares regression, Pimentel (1979) defines that axis as the line which passes as close as possible to all individuals no matter how they are distributed in the data space.

Each succeeding axis represents the next orthogonal axis of variance. Additional axes are extracted until all variance in the data space is accounted for. Each axis is independent and together they account for $100 \%$ of the total sample variance.

In algebraic form each axis is represented by a eigenvalue, or component, derived from the variance-covariance matrix $\left(S^{2}\right)$. In the characteristic equation provided by Pimentel (1979):

$$
S^{2}-1_{i} I=0
$$

$l_{i}$ represents the characteristic roots $l_{1}, l_{2}, l_{3} \ldots$ and $I$ is an identity matrix. An eigenvector of coefficients $\left(a_{i}\right)$ is derived for each component using 
the equation:

$$
\left(S^{2}-1_{i} I\right) a_{i}=0
$$

where $a_{i}^{\prime} a_{i}$ is the eigenvector scalar. Each coefficient is a weight representing the relative contribution to the component made by the original variable. When applied to variables, eigenvectors produce component scores for each individual.

Interpreting Principal Component Analysis

PCA produces independent components accounting for successively less variation. The first two or three components usually represent most of the variation in the data space. Both Morrison (1967) and Pimentel (1972) advise retaining only the first few components. They believe that little interpretable information emerges once $75 \%$ to $80 \%$ of the variance is accounted for in the first few components. Later components contribute little to the analysis and usually can be dropped with no information loss. The original data structure is thereby reduced to two or three latent variables representing size and shape underlying the discernable variation recorded in measured attributes (Morrison 1967).

The first component is often considered a size component when certain conditions are met (Gould 1966, Pimentel 1979, Morrison 1967, Mosimann \& James 1979). A component meets these criteria when the values of the first eigenvector are of the same sign and the vector equal to a theoretical vector of isometry (a vector composed of values equal to $1 / \sqrt{ } \mathrm{p}$ where $\mathrm{p}$ equals the 
number of variables).

A wealth of previous investigations and theoretical discussions support the use of PCA in analyses designed to explore variation in form within a population (for detailed discussions see the previously cited sources). For example, in the first demonstration of the its practical application, Jolicoeur and Mosimann (1960:353) concluded that PCA "... is best suited to disclose the nature and the magnitude of size and shape variation". Pimentel (1979) agreed and explained that components are a response to one or more causal stimuli (genetic, environmental or both) that affect morphology.

PCA also provides a means of assessing the nature of morphological variation through time. A sample distributed along a single morphological continuum might suggest gradual evolutionary change. In contrast, a single shotgun blast cluster likely represents random variation through time. Finally, a sample distributed in a number of morphological clusters represents discontinuous evolutionary change, the type of variation predicted by punctuated equilibrium.

\section{$\underline{\text { Analysis }}$}

Prior to the PCA, I performed two preliminary analyses on the 18 variables discussed above (see Tables III \& IV). In the first investigation, a ttest performed on each variable identified significant differences among the mean values for each group. This test was used to determine if the groups consistently differed from one another on every dimension.

In the second test, I performed a cluster analysis to discover if the 
temporal groups had any morphological integrity. The unweighted pairgroup method was applied to the logged variables. This agglomerative method is generally preferred, because it distorts the original Euclidean space less than single or complete linkage cluster analysis (Pimentel 1979).

Following the preliminary analyses, I performed a principal component analysis on the $\log$ transformed dimensions. Component scores were graphed using bivariate and box plots to assist in identifying patterns of variation among the thirty-three specimens in my sample.

ANOVA and Tukey's HSD were used with each component to determine if the mean scores for the temporal groups varied significantly. Where significant differences appeared, the component structure was examined to determine the nature (isometry or allometry) of the variation.

As a final step, I performed a cluster analysis on the scores of the significant components. This analysis was used to confirm the existence of the groups identified by the Tukey's HSD. 


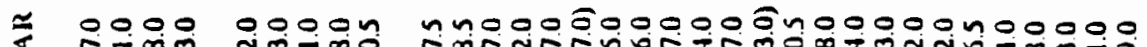

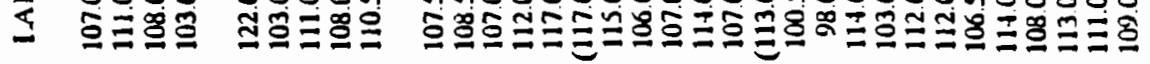

\% onoo 00000 no000000000600000000000n

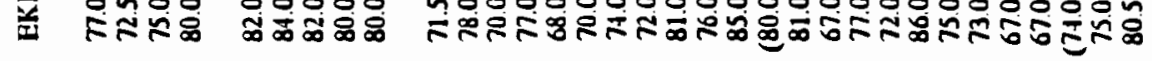

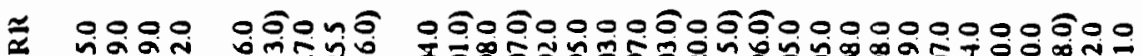

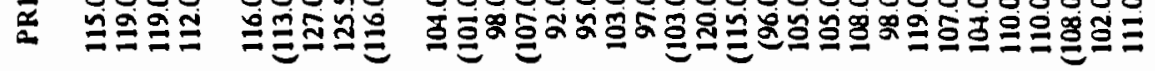

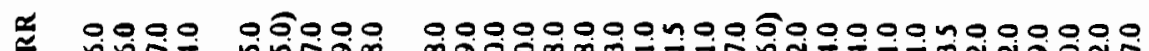

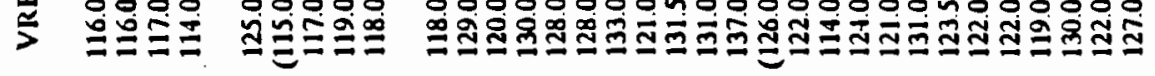

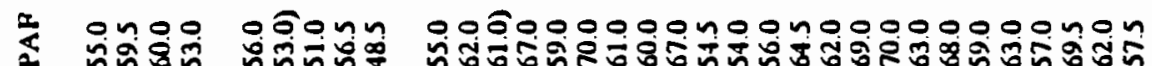

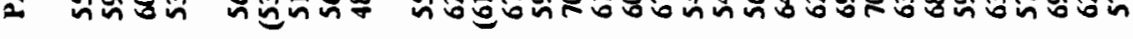

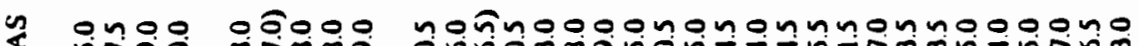

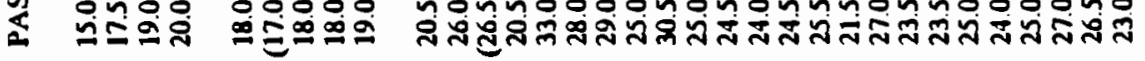

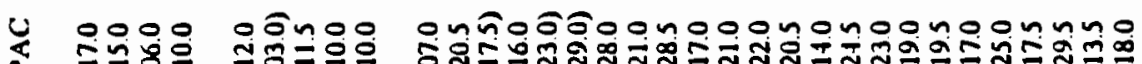

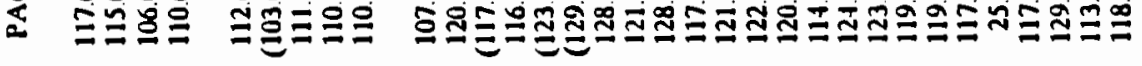

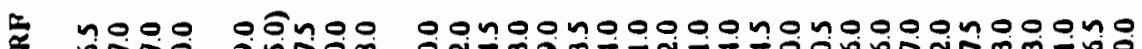

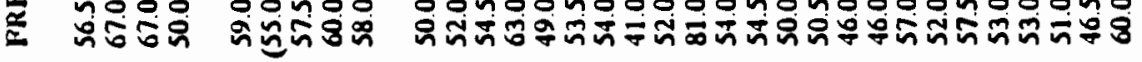

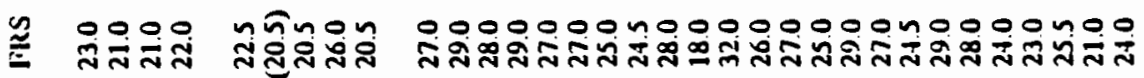

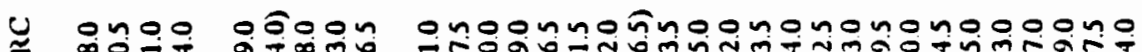

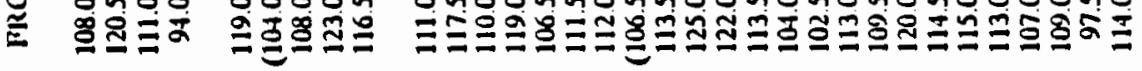

8 0000 00000 00000000no0000000no00noo

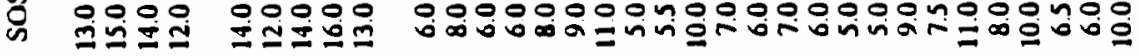

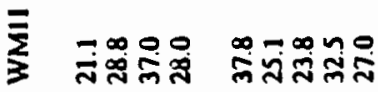

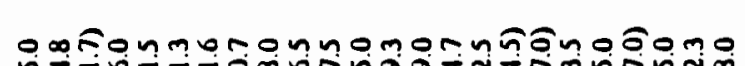

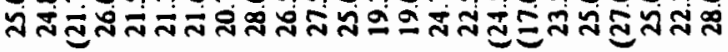

สิตํํำำด

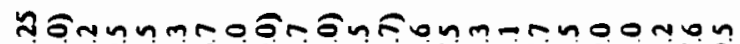

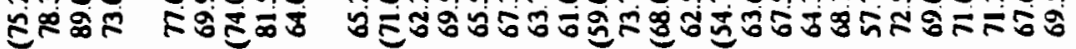

E $\infty$ no nonoo o-monmrnoronnoto-noobno

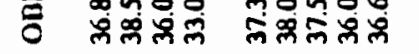

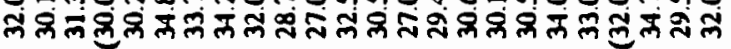

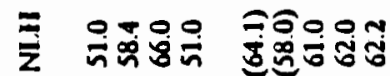

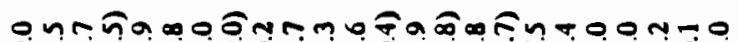

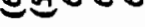

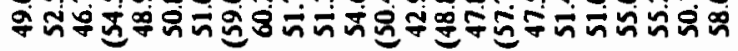

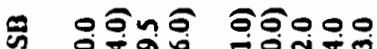

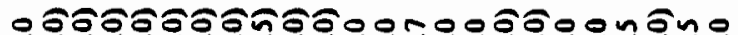

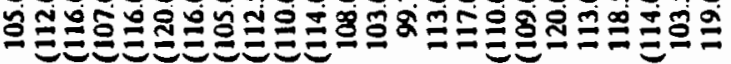

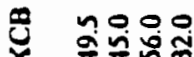

oㅇำ

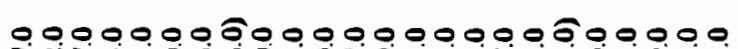

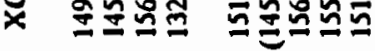

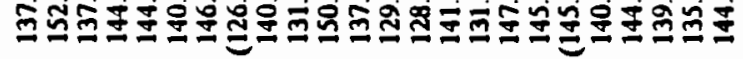

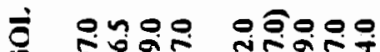

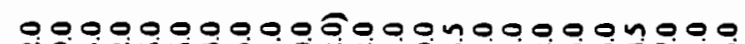

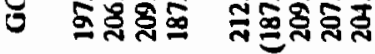

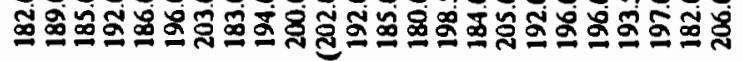
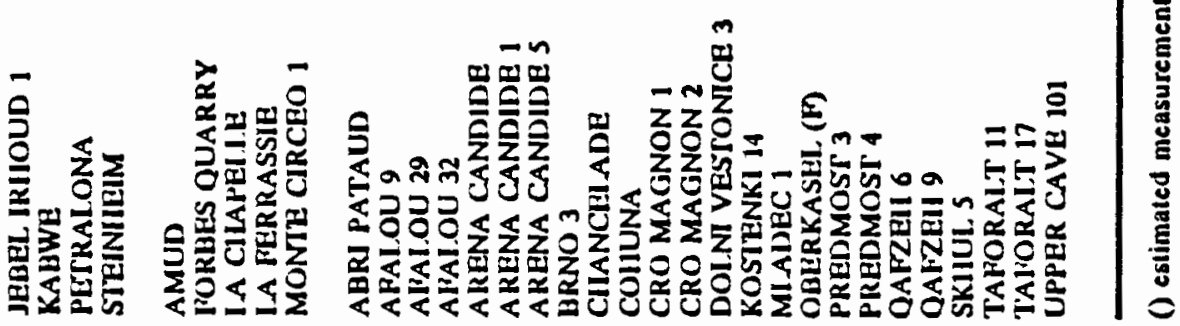


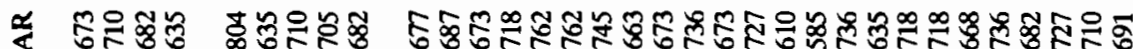

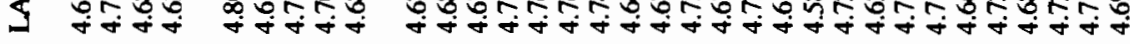

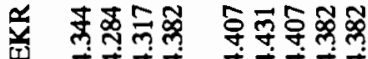

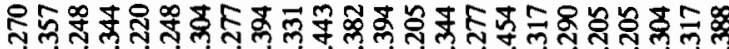

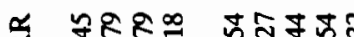

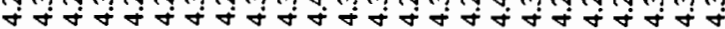

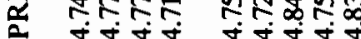

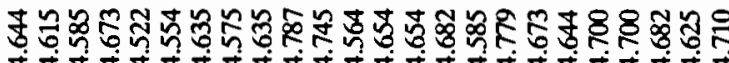

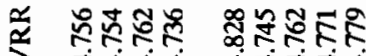

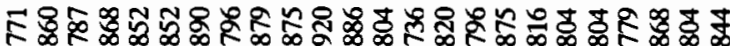

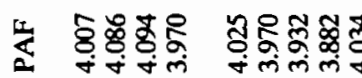

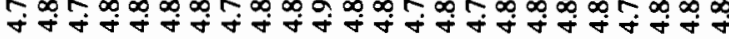

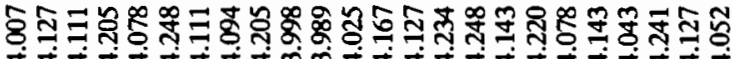

约

4ivinic

శิ

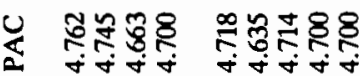

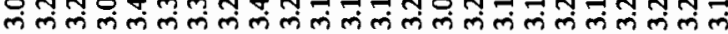

$\lesssim \dot{+} \dot{+} \dot{+}$

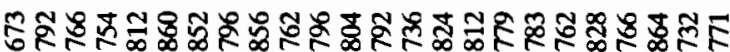

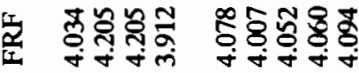

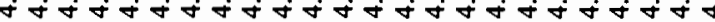

జ

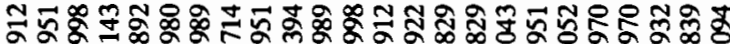

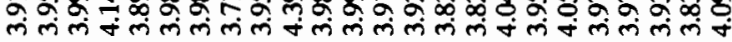

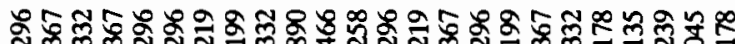

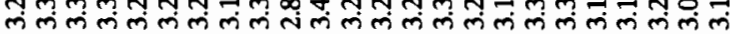

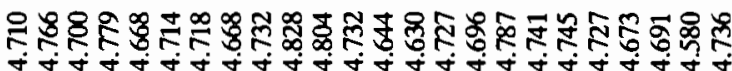

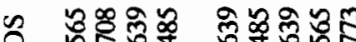

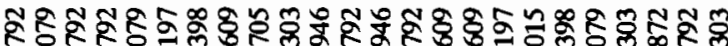
O जึ่ - ن

₹

3 लंक लंलिलंखें

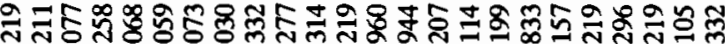

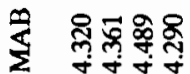

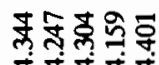

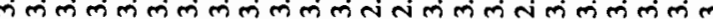

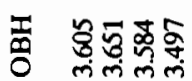

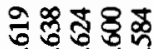

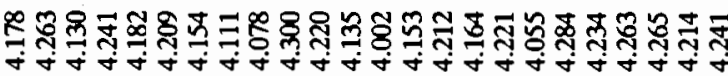

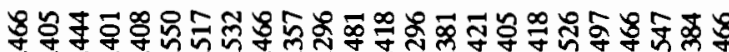

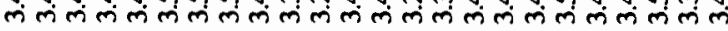

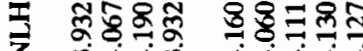

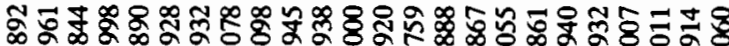

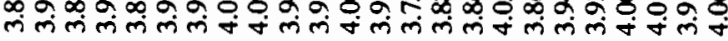

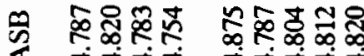

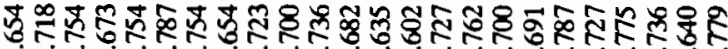

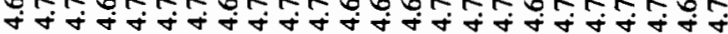

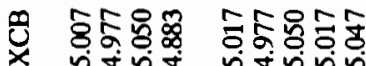

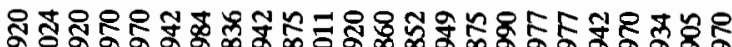

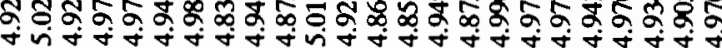

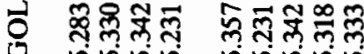

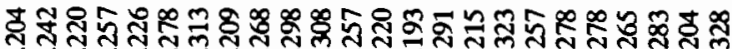
vivivivin

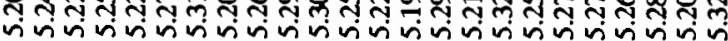
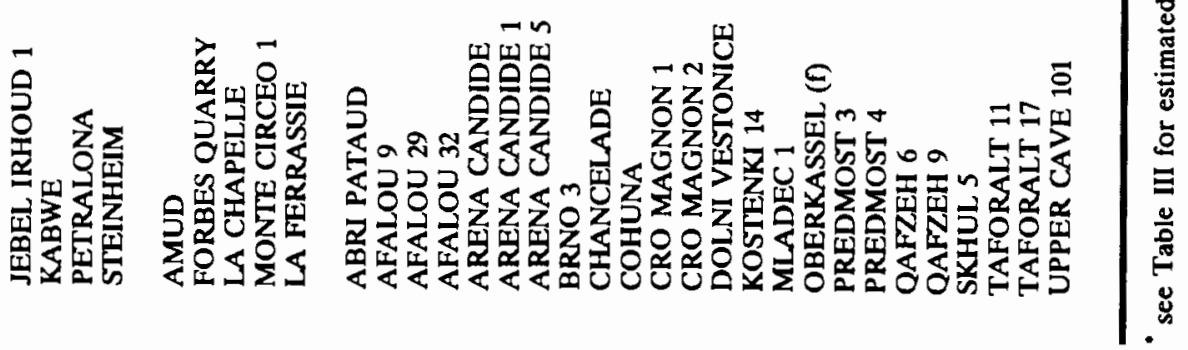


\title{
CHAPTER III
}

\author{
RESULTS
}

\section{UNIVARIATE ANALYSIS}

Table $\mathrm{V}$ provides the mean and standard deviation for each dimension by group. I used Student's t-test ${ }^{4}$ to determine which groups had significantly different mean values (Table VI). As expected, no two groups are identical. Significant differences occur in some measurements when comparing any two groups, and no single dimension distinguishes all three temporal groups.

Two measurements, for example, significantly differ between Würm I and mid Pleistocene Homo sapiens. Mean values of both GOL and EKR are larger in the Würm I than in the mid Pleistocene sample.

In contrast, the mid Pleistocene values for those same two variables are

${ }^{4}$ I used Student's t-test in the tradition established by the previously cited analyses of evolutionary tempo. It should be noted, however, that the use of a t-test is questionable. A t-test assumes the data are normally distributed and that the variances are approximately equal. Clearly, there is no way to test for normal distribution in very small samples (a common problem in paleontological data).

An Analysis of Variance (ANOVA) provides a partial solution. ANOVA is robust in cases of nonnormal distribution and unequal variance and, unlike the t-test, it does not underestimate the probability of type I error when testing more than two groups (Zar 1984). Unfortunately, ANOVA determines that differences exist between groups, but not which groups are different. Like ANOVA, Tukey's HSD does not underestimate the probability of type I error, and can be used to pairwise test each group across all 18 variables. Though statistically more appealing, to perform 18 ANOVAs and minimally 54 pairwise tests is a formidable challenge in a test such as this. 
not significantly different than for the post Göttweig. Two additional variables, XCB and NLH, are not significantly different for these two groups.

Interestingly, no particular pattern in the variation of cranial morphology emerges among those four variables. $\mathrm{XCB}$ and GOL measure calvarium dimensions, while NLH and EKR measure facial attributes.

The Würm I and post Göttweig samples share only three variables without significant difference in mean value. They are FRC, FRF, and LAR. These variables, in fact, are the only measurements not significantly different in all three groups. All three variables measure the calvarium.

In addition to trapping this analysis in a quagmire of unresolvable methodological problems, the univariate analysis disclosed few details regarding the morphological relationships of the three temporal samples. Contradictory results among the variables only obscured group similarity and dissimilarity. Very little information emerges from a univariate analysis of evolutionary tempo, but a great deal of time is lost. 


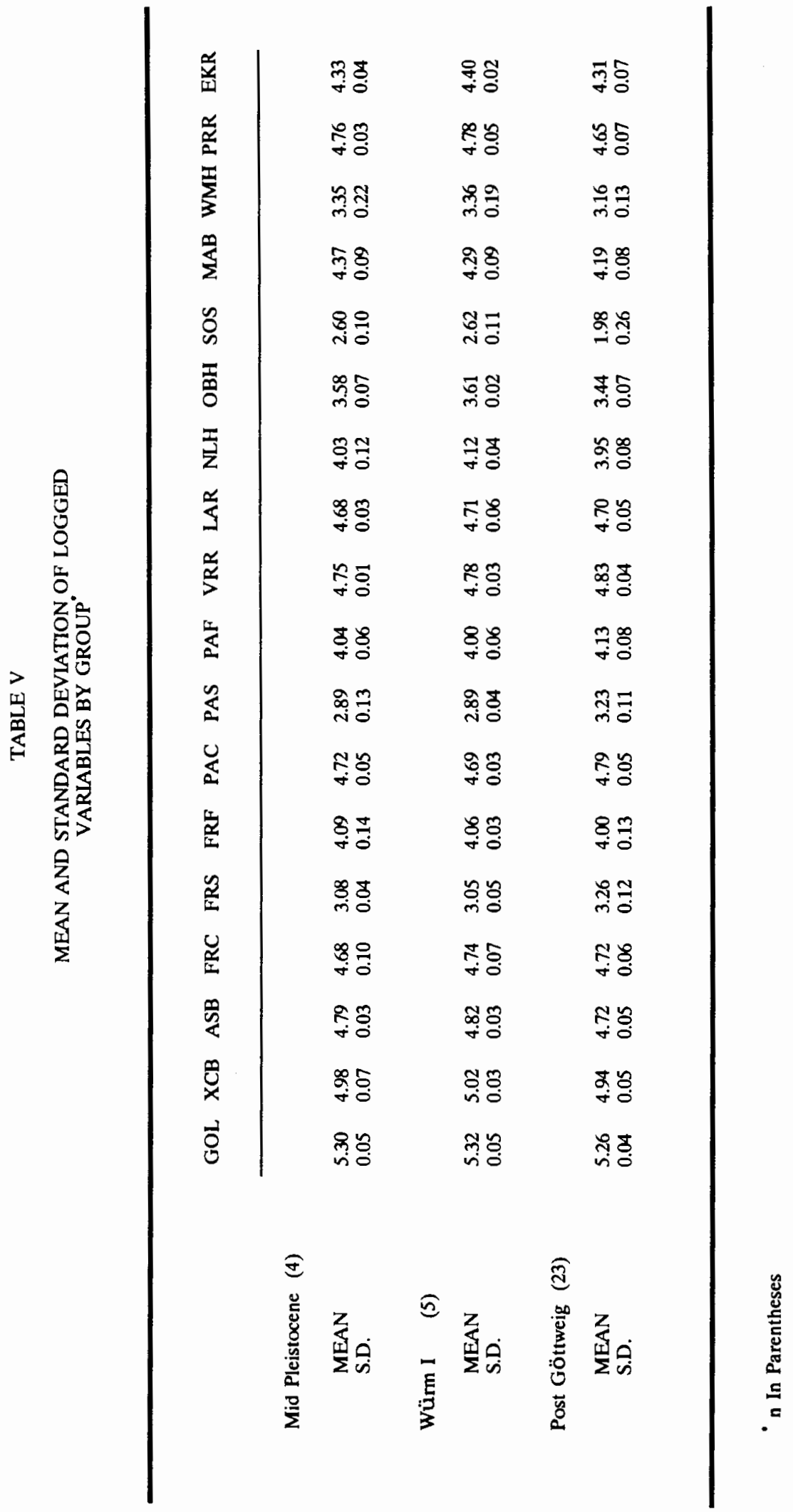



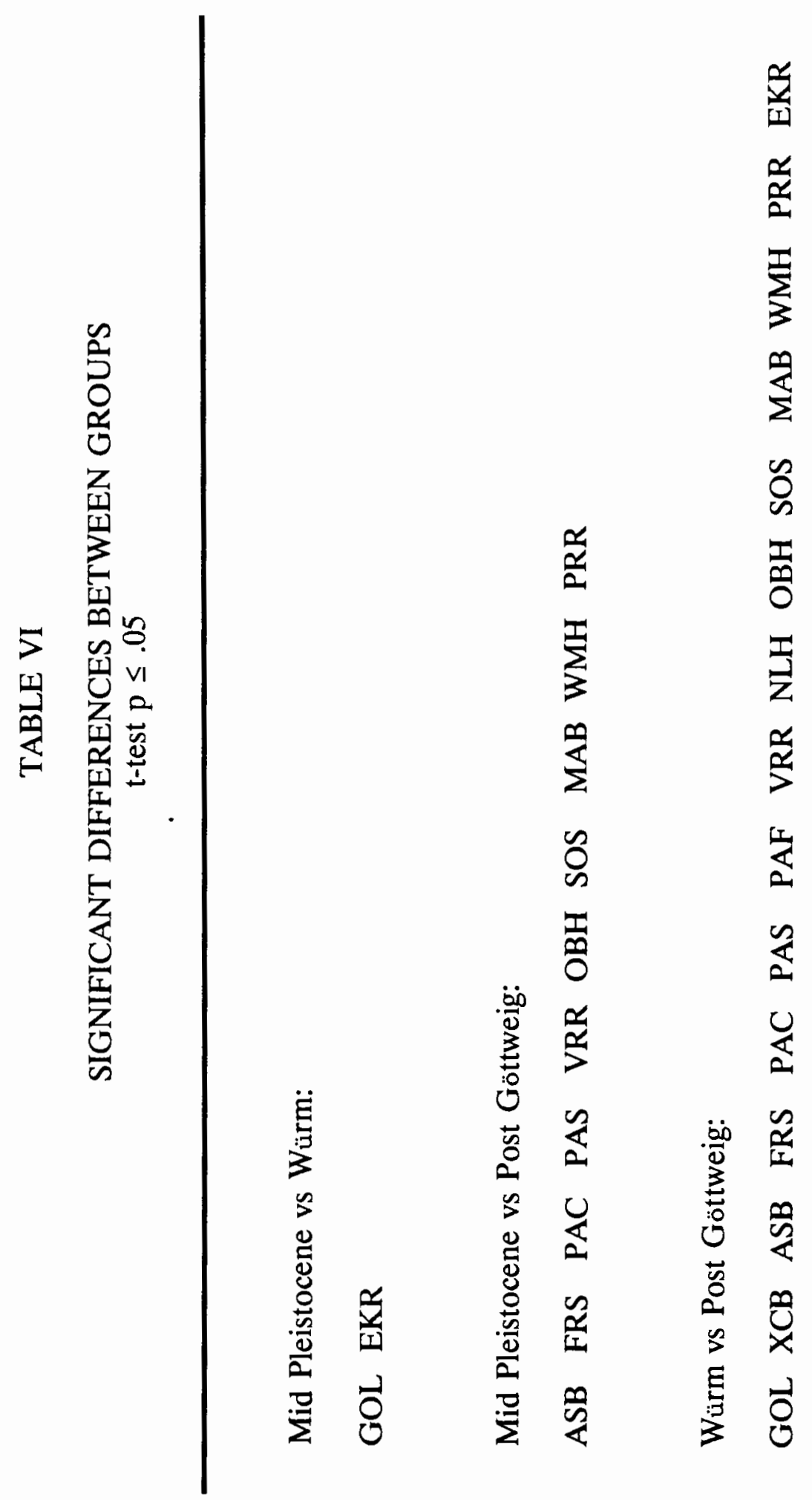


\section{MULTIVARIATE ANALYSES}

The preliminary cluster analysis of logged variables clearly separated the post Göttweig group from the earlier mid Pleistocene and Würm I groups (Figure 3). These results support the observable distinction between archaic and modern Homo sapiens.

I used PCA to further clarify the morphological relationships identified in the cluster analysis. Based on component structure, I determined if the variation was patterned. Further, I attempted to discover if the variation was continuous or clustered in discrete groups.

Of the original 18 components generated by the PCA, only the first three were retained for analysis. A skree plot (Figure 4) shows that eigenvalues level off after the third component. Together, the first three components account for $83 \%$ of the sample variance (see Table VII).

Of the three components retained, the first and third provide interpretable results. Mirroring the cluster analysis, these two component's scores divide the three temporal samples into two distinct morphological groups. The second component, however, is difficult to interpret. Only two measurements load on component II, and scores for the three groups appear randomly mixed. Scores for the first three components are provided in Tables VIII, IX, and X.

Component score means for all three groups were tested for significant differences using ANOVA and Tukey's HSD. Significant differences are reported in Table XI. Results show that component I mid Pleistocene and 
Würm I mean scores are not different, while both significantly differ from the post Göttweig mean.

In contrast, mean scores for the three groups were not significantly different on component III. A t-test was performed using the mid Pleistocene and Würm I pooled mean to determine if small sample size affected the individual group results. This $\mathrm{t}$-test indicated that the pooled mean significantly differed from the post Göttweig mean.

Box plots in Figures 5 and 6 illustrate the same differences in mean scores as revealed by the t-tests. In addition, they show the range of variation in all three groups on the first and third components. On the first component the post Göttweig group is clearly distinct from the earlier Würm and mid Pleistocene samples.

By contrast, group scores unquestionably overlap on the third component. Nonetheless, the difference in mean values is apparent. The mid Pleistocene and Würm means are nearly the same and both differ from the post Göttweig mean score.

A bivariate plot (Figure 7) of components I and III further clarifies the morphological relationship of the later group with the two early groups. The post Göttweig sample clearly clusters apart from the mid Pleistocene and Würm groups. In addition, the ranges of variation for the two early groups completely overlap.

A second cluster analysis supported the Tukey HSD results. An analysis of the scores for the first three components once again separated the post 
Göttweig group from two early groups (Figure 8). In addition, this analysis indicated that the Cohuna cranium is an outlier distinct from the early and the post Göttweig groups.

\section{Interpretation Of Components}

As discussed in the previous chapter, the first component is often considered a size component when certain conditions are met. In this analysis, the eigenvector of the first component was neither equal to a theoretical vector of isometry nor were the values all of the same sign. These results indicate that variation present on the first and all subsequent components was produced by both size and shape.

Patterns in the component loadings permit inferences regarding the size and shape variation present on each component (see Table VII). For example, FRS, PAC, PAS, PAF, and VRR load highest on component III. These variables measure calvarium height. This indicates that component III distinguishes flat from elevated crania.

In contrast, facial variables, such as SOS, MAB, OBH, NLH, PRR, EKR, and ASB load highest on component I. Thus, component I segregates on the basis of facial form.

As previously indicated, only two variables load on component II. Unfortunately, the meaning of the meaning of this result is difficult to interpret. WMH and FRC measure the face and calvarium respectively and there is no obvious relationship between the two dimensions. Interestingly, WMH, a measure of maxillary inflation, also loads highly on component $\mathbf{I}$. 
0.000

DISTAMCE

1.000

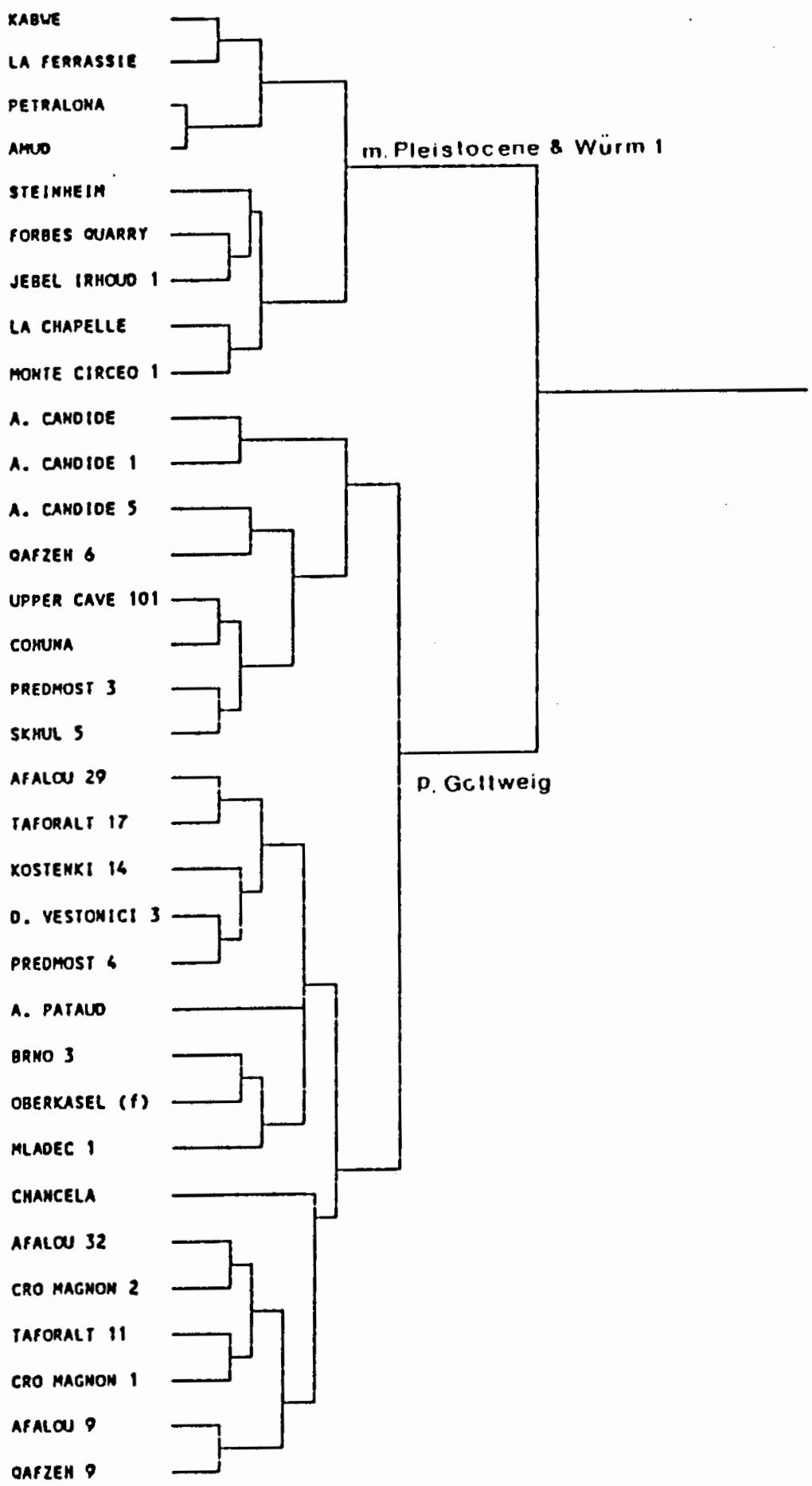

Figure 3. Dendrogram produced by an unweighted pairgroup cluster analysis of logged measurements. 


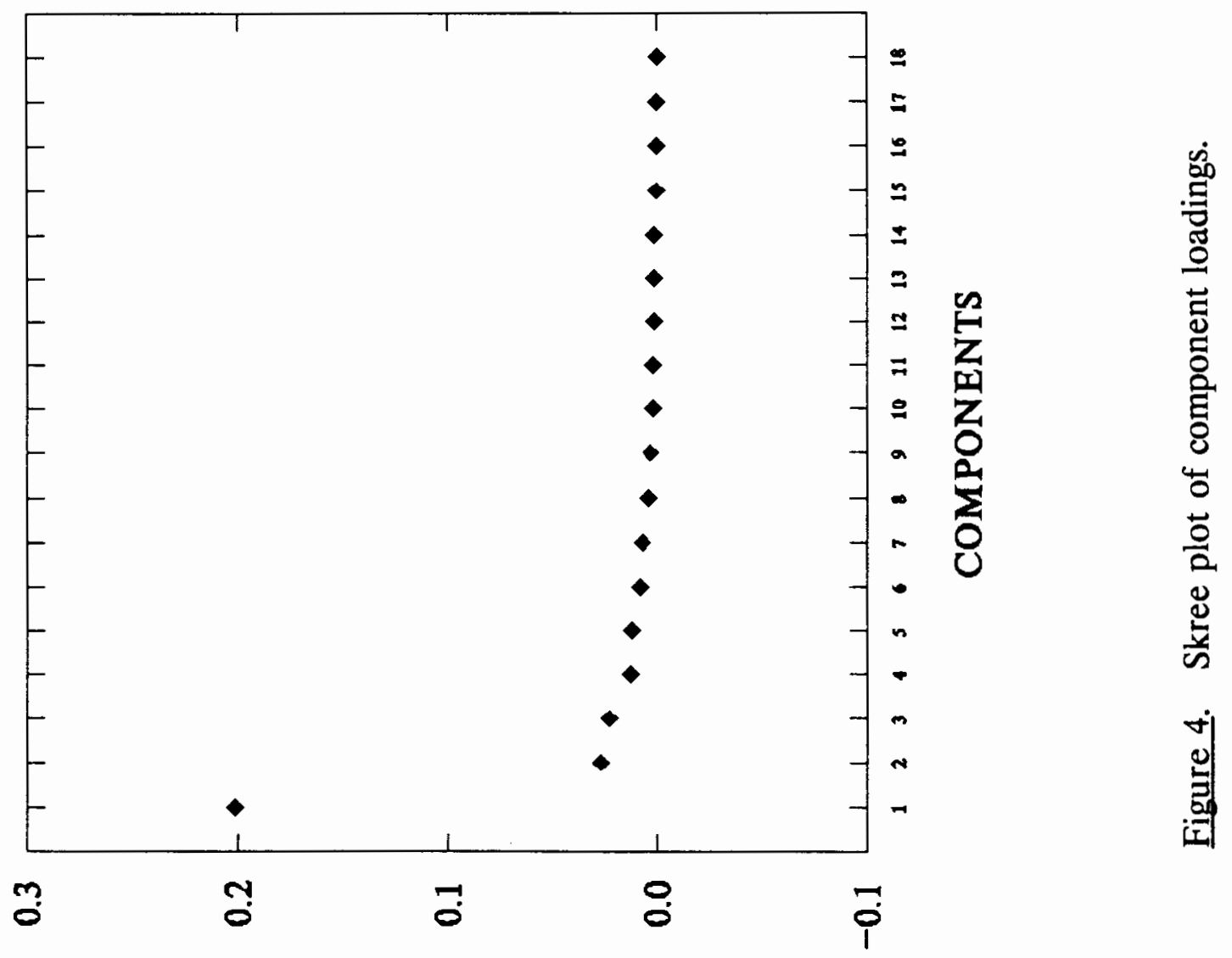

GกTVANGDIZ 
TABLE VII

LOADINGS AND VARIANCE FOR COMPONENTS I - V

\begin{tabular}{lrrrrr} 
& \multicolumn{1}{c}{ I } & \multicolumn{1}{c}{ II } & \multicolumn{1}{c}{ III } & \multicolumn{1}{c}{ IV } & \multicolumn{1}{c}{ V } \\
\hline LGOL & 0.034 & 0.014 & 0.015 & 0.011 & 0.005 \\
LXCB & 0.038 & 0.009 & 0.012 & 0.029 & 0.000 \\
LASB & 0.046 & 0.004 & 0.014 & 0.017 & -0.018 \\
LNLH & 0.067 & 0.047 & 0.003 & -0.000 & -0.034 \\
LOBH & 0.069 & -0.008 & -0.016 & 0.014 & -0.045 \\
LMAB & 0.076 & 0.030 & 0.006 & -0.007 & 0.001 \\
LWMH & 0.109 & 0.124 & 0.020 & -0.013 & -0.027 \\
LSOS & 0.353 & -0.070 & 0.044 & 0.016 & -0.006 \\
LFRC & 0.016 & 0.028 & 0.024 & 0.020 & 0.030 \\
LFRS & -0.095 & 0.013 & 0.023 & 0.088 & 0.007 \\
LFRF & 0.085 & 0.026 & 0.036 & -0.020 & 0.073 \\
LPAC & -0.034 & -0.003 & 0.031 & 0.013 & -0.004 \\
LPAS & -0.136 & -0.021 & 0.118 & -0.033 & -0.023 \\
LPAF & -0.061 & 0.007 & 0.024 & 0.023 & -0.002 \\
LVRR & -0.017 & 0.016 & 0.032 & 0.009 & 0.010 \\
LPRR & 0.064 & 0.016 & -0.015 & -0.003 & 0.025 \\
LEKR & 0.024 & 0.023 & -0.013 & 0.017 & 0.009 \\
LLAR & 0.008 & 0.009 & 0.021 & 0.005 & -0.002 \\
\hline
\end{tabular}

EIGENVALUE
0.201
0.027
0.023
0.013
0.012

PERCENT OF TOTAL VARIANCE EXPLAINED

$\begin{array}{lllll}66.283 & 8.869 & 7.536 & 4.189 & 3.921\end{array}$

CUMULATIVE VARIANCE EXPLAINED

$\begin{array}{lllll}66.283 & 75.152 & 82.688 & 86.877 & 90.798\end{array}$


TABLE VIII

RANK ORDER OF COMPONENT I SCORES

\begin{tabular}{lcc} 
& GROUP & SCORE \\
\cline { 2 - 3 } OBERKASEL (Female) & 3 & -0.637 \\
BRNO 3 & 3 & -0.590 \\
MLADEC 1 & 3 & -0.526 \\
KOSTENKI 14 & 3 & -0.513 \\
CHANCELADE & 3 & -0.483 \\
AFALOU 29 & 3 & -0.452 \\
TAFORALT 17 & 3 & -0.408 \\
DOLNI VESTONICI 3 & 3 & -0.372 \\
CRO MAGNON 2 & 3 & -0.334 \\
PREDMOST 4 & 3 & -0.328 \\
ABRI PATAUD & 3 & -0.310 \\
ARENA CANDIDE & 3 & -0.304 \\
TAFORALT 11 & 3 & -0.296 \\
AFALOU 32 & 3 & -0.270 \\
CRO MAGNON 1 & 3 & -0.215 \\
AFALOU 9 & 3 & -0.157 \\
ARENA CANDIDE 1 & 3 & -0.129 \\
QAFZEH 9 & 3 & -0.085 \\
PREDMOST 3 & 3 & 0.053 \\
CANDIDE 5 & 3 & 0.061 \\
SKHUL 5 & 3 & 0.140 \\
QAFZEH 6 & 3 & 0.154 \\
UPPER CAVE 101 & 3 & 0.207 \\
COHUNA & 3 & 0.263 \\
STEINHEIM & 1 & 0.367 \\
FORBES QUARRY & 2 & 0.480 \\
JEBEL IRHOUD 1 & 1 & 0.507 \\
MONTE CIRCEO 1 & 2 & 0.552 \\
LA CHAPELLE & 2 & 0.628 \\
AMUD & 2 & 0.721 \\
KABWE & 1 & 0.728 \\
PETRALONA & 1 & 0.745 \\
LA FERRASSI & 2 & 0.802 \\
& &
\end{tabular}


TABLE IX

RANK ORDER OF COMPONENT II SCORES

\begin{tabular}{|c|c|c|}
\hline & GROUP & SCORE \\
\hline PREDMOST 4 & 3 & -0.279 \\
\hline ARENA CANDIDE 5 & 3 & -0.260 \\
\hline JEBEL IRHOUD 1 & 1 & -0.225 \\
\hline KOSTENKI 14 & 3 & -0.203 \\
\hline ARENA CANDIDE & 3 & -0.200 \\
\hline VESTONICE 3 & 3 & - 0.192 \\
\hline ARENA CANDIDE 1 & 3 & -0.187 \\
\hline LA CHAPELLE & 2 & -0.146 \\
\hline QAFZEH 6 & 3 & -0.145 \\
\hline STEINHEIM & 1 & -0.100 \\
\hline GIBRALTER & 2 & -0.097 \\
\hline MONTE CIRCEO 1 & 2 & - 0.049 \\
\hline AFALOU 29 & 3 & -0.043 \\
\hline TAFORALT 17 & 3 & -0.040 \\
\hline SKHUL 5 & 3 & - 0.035 \\
\hline KABWE & 1 & -0.009 \\
\hline BRNO 3 & 3 & -0.002 \\
\hline QAFZEH 9 & 3 & -0.001 \\
\hline AFALOU 9 & 3 & 0.037 \\
\hline OBERKASEL (Female) & 3 & 0.047 \\
\hline COHUNA & 3 & 0.053 \\
\hline PREDMOST 3 & 3 & 0.054 \\
\hline UPPER CAVE 101 & 3 & 0.088 \\
\hline LA FERRASSI & 2 & 0.091 \\
\hline ABRI PATAUD & 3 & 0.103 \\
\hline TAFORALT 11 & 3 & 0.113 \\
\hline CRO MAGNON 2 & 3 & 0.141 \\
\hline MLADEC 1 & 3 & 0.211 \\
\hline CRO MAGON 1 & 3 & 0.220 \\
\hline PETRALONA & 1 & 0.256 \\
\hline AMUD & 2 & 0.261 \\
\hline CHANCELADE & 3 & 0.270 \\
\hline AFALOU 32 & 3 & 0.272 \\
\hline
\end{tabular}


TABLE $X$

RANK ORDER OF COMPONENT III SCORES

\begin{tabular}{|c|c|c|}
\hline & GROUP & SCORE \\
\hline JEBEL IRHOUD 1 & 1 & -0.272 \\
\hline FORBES QUARRY & 2 & -0.265 \\
\hline ABRI PATAUD & 3 & -0.252 \\
\hline BRNO 3 & 3 & -0.207 \\
\hline MLADEC 1 & 3 & -0.173 \\
\hline STEINHEIM & 1 & -0.132 \\
\hline LA CHAPELLE & 2 & -0.128 \\
\hline KOSTENKI 14 & 3 & -0.122 \\
\hline TAFORALT 17 & 3 & -0.095 \\
\hline DOLNI VESTONICI 3 & 3 & -0.084 \\
\hline AFALOU 32 & 3 & -0.083 \\
\hline MONTE CIRCEO 1 & 2 & -0.082 \\
\hline CRO MAGNON 2 & 3 & -0.055 \\
\hline OBERKASEL (f) & 3 & -0.044 \\
\hline PREDMOST 4 & 3 & -0.030 \\
\hline KABWE & 1 & -0.008 \\
\hline AFALOU 29 & 3 & 0.010 \\
\hline LA FERRASSI & 2 & 0.019 \\
\hline AMUD & 2 & 0.030 \\
\hline QAFZEH 9 & 3 & 0.037 \\
\hline PETRALONA & 1 & 0.054 \\
\hline PREDMOST 3 & 3 & 0.073 \\
\hline CRO MAGNON 1 & 3 & 0.077 \\
\hline TAFORALT 11 & 3 & 0.090 \\
\hline UPPER CAVE 101 & 3 & 0.093 \\
\hline SKHUL 5 & 3 & 0.099 \\
\hline AFALOU 9 & 3 & 0.132 \\
\hline CHANCELADE & 3 & 0.162 \\
\hline QAFZEH 6 & 3 & 0.171 \\
\hline COHUNA & 3 & 0.187 \\
\hline ARENA CANDIDE 1 & 3 & 0.235 \\
\hline ARENA CANDIDE & 3 & 0.277 \\
\hline ARENA CANDIDE 5 & 3 & 0.288 \\
\hline
\end{tabular}


TABLE XI

COMPONENT MEANS AND SIGNIFICANT $(\mathrm{p} \leq .05)$ DIFFERENCES

GROUP

(N)

COMPONENT MEANS

I

II

III

Mid Pleistocene

(4)

.587

$-.020$

$-.090$

Würm I (5)

.637

.012

$-.085$

Post Göttweig (24)

$-.230$

.001

.033

\section{ANOVA}

\section{COMPONENT I}

Between groups

SS

DF

MS

F

$\mathbf{P}$

Within groups

4.678

2

2.339

40.057

.000

1.752

30

0.058

TUKEY'S HSD

MATRIX OF PAIRWISE COMPARISON PROBABILITIES

Mid. Pleist.

Mid Pleist.

Würm I

Post Gött.
1.000

.924

.000
Würm I

1.000

.000
Post Gött.

1.000

Student's t-test

\section{COMPONENT III}

MEAN

Mid Pleistocene \& Würm I

POOLED mean

Post Göttweig
$-.087$

.033
Pooled Variance t 


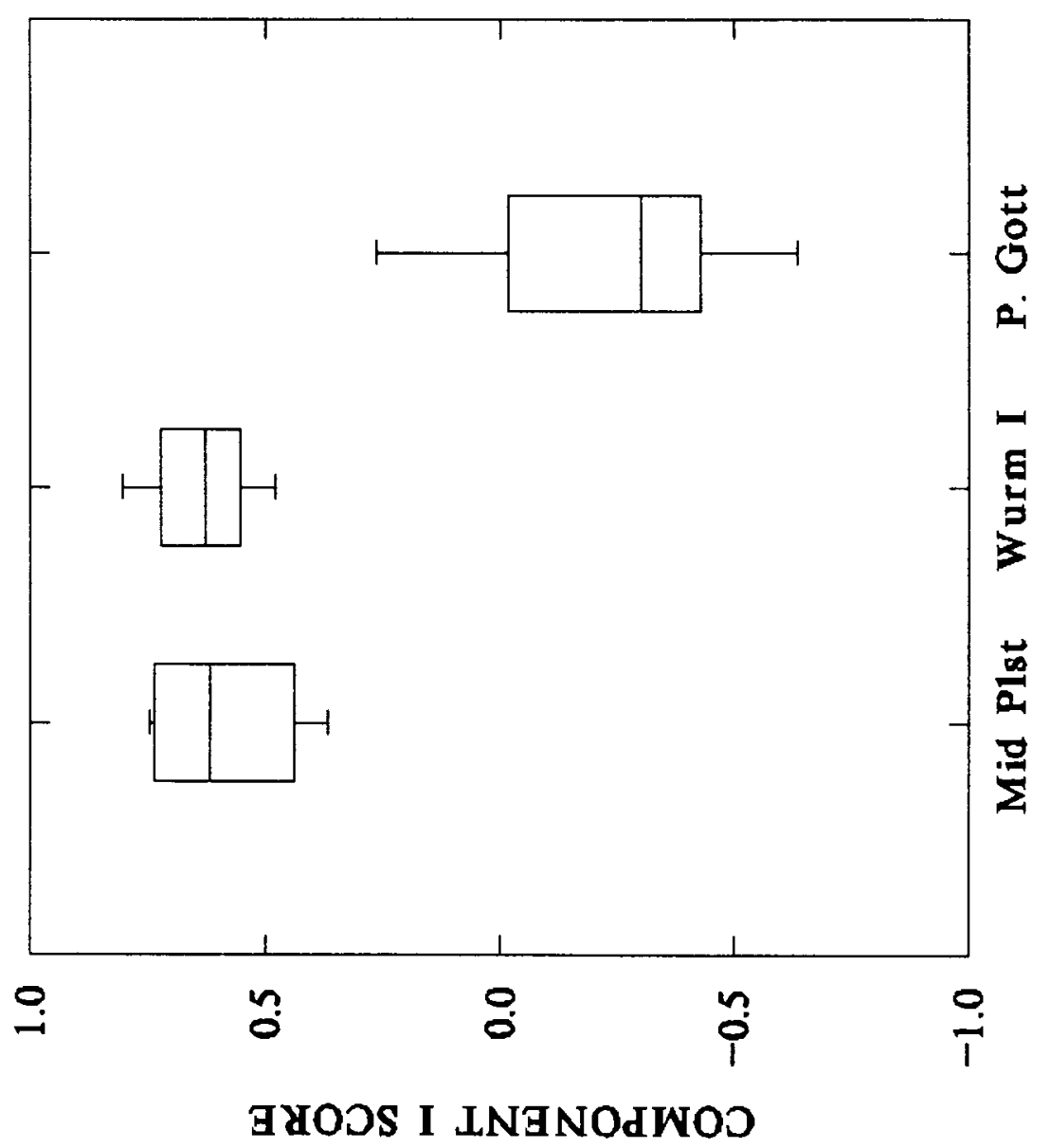

官

อ

릉

4

흠

苨

ज्ञ

GYODS I LNGNOdWOD 


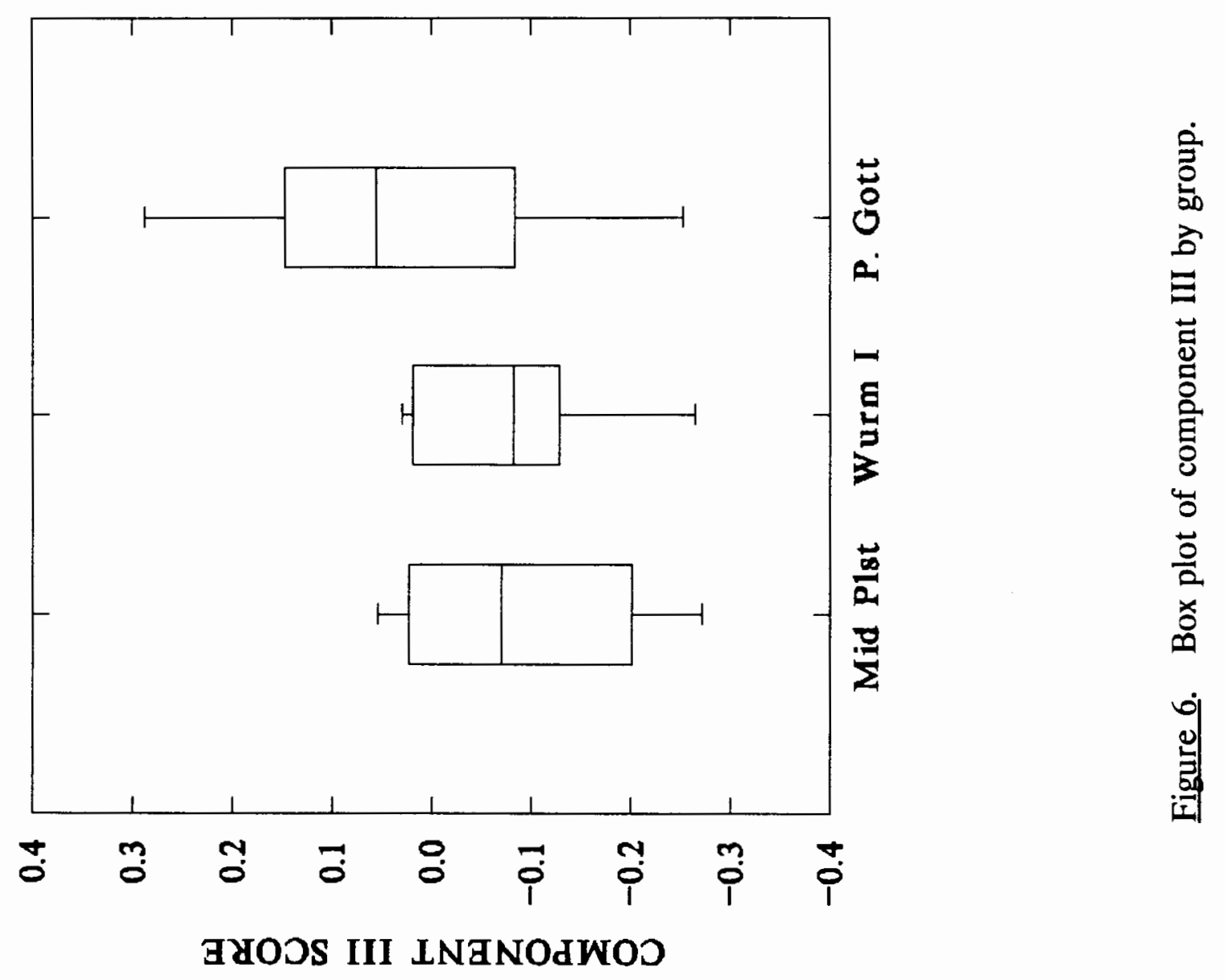



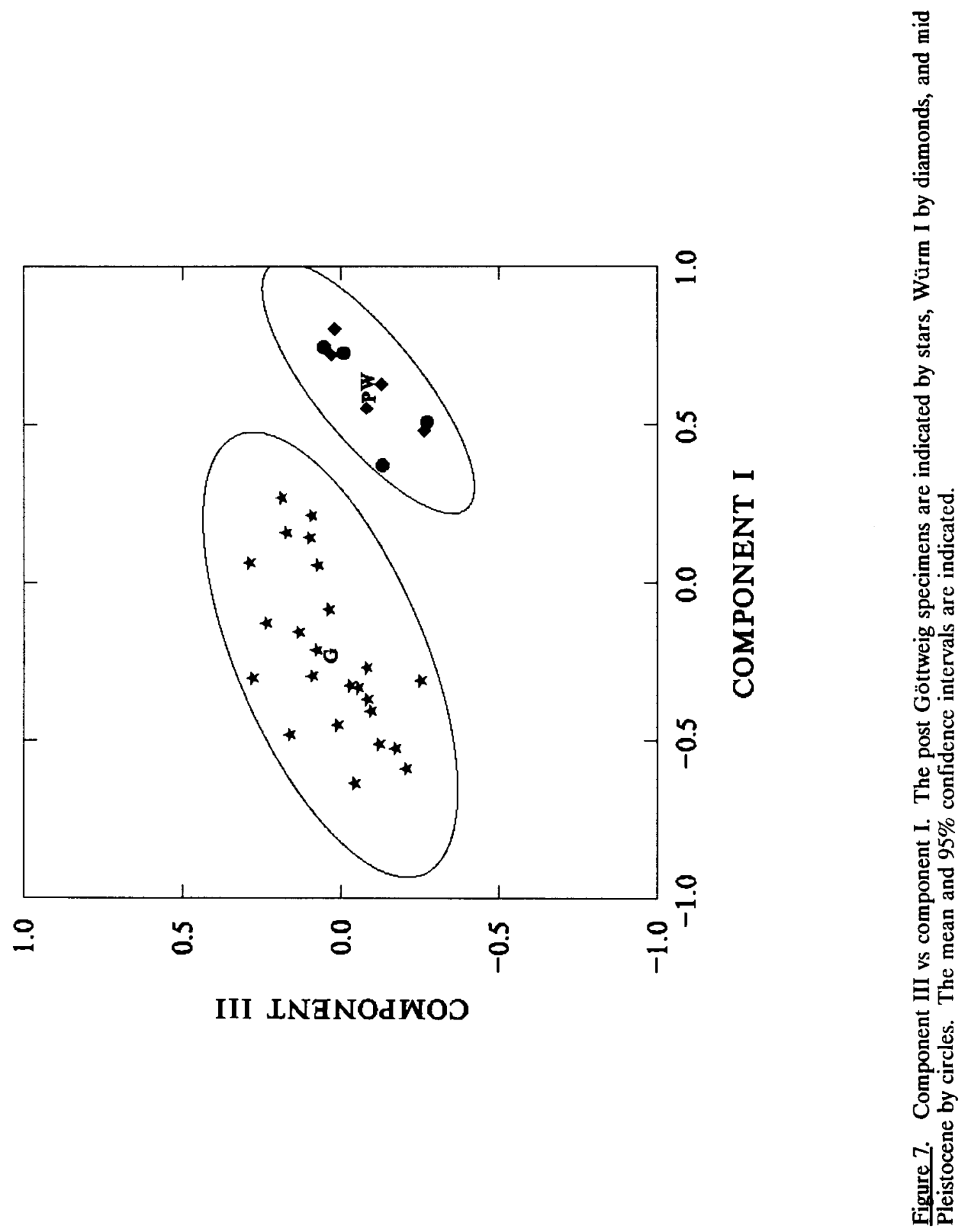
0.000

oistances

0.500

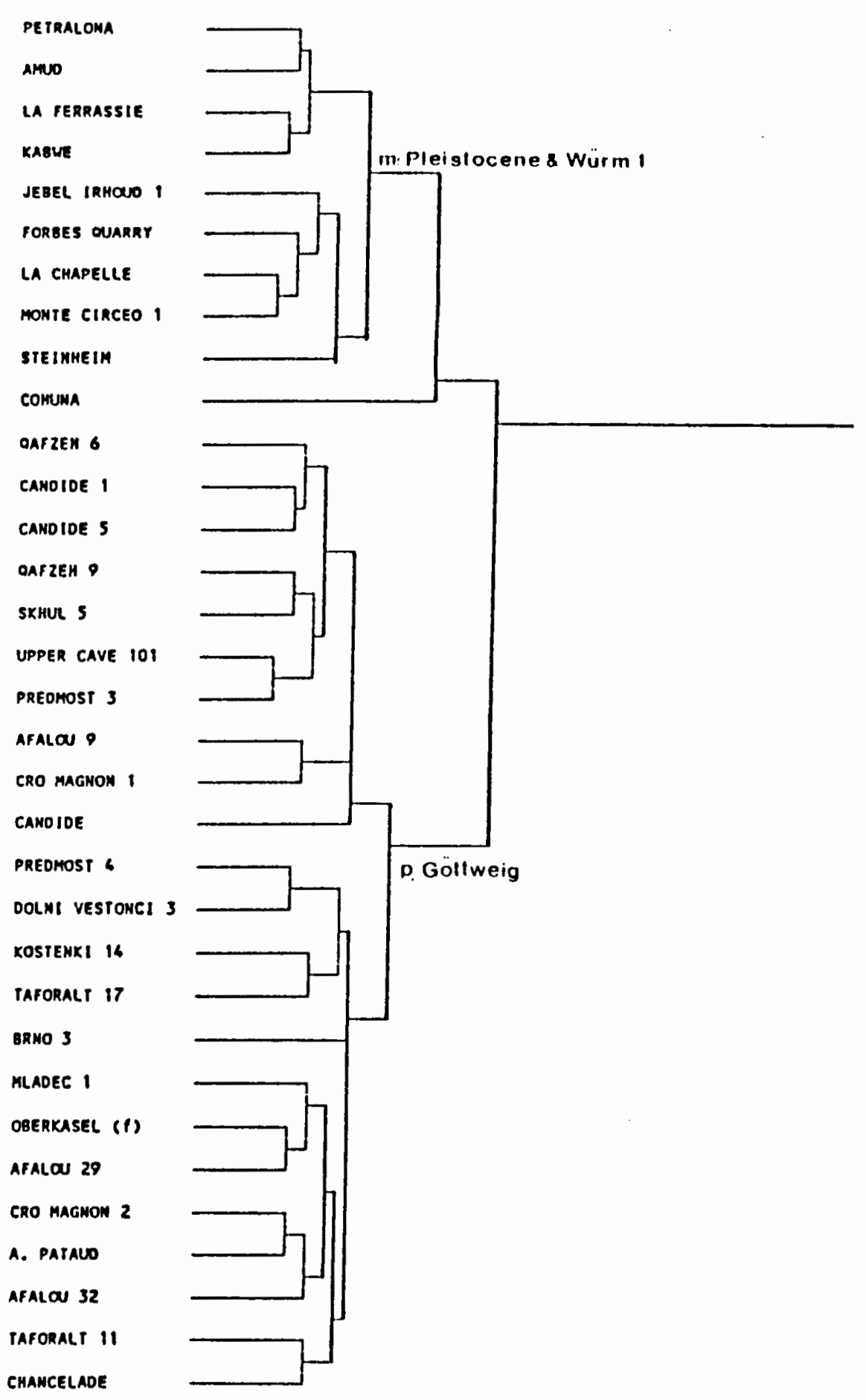

Figure 8. Dendrogram produced by an unweighted pairgroup cluster analysis of the first three component scores. 


\section{CHAPTER IV}

\section{DISCUSSION}

This study addressed several questions pertaining to the morphological expression of evolutionary stasis. It demonstrated that morphometric analysis more convincingly identifies stasis than the univariate techniques commonly used in the past. Furthermore, this study shows that crudely dated fossil samples are not an obstacle to analysis of evolutionary tempo.

The latter point is of substantial interest since rough dating is the rule rather than the exception in paleoanthropology. Few of the fossils that fall between the ranges of carbon 14 and potassium argon dating possess secure chronology. As discussed previously, the dating problems for some of the most important hominid fossils is even more grim. Their lost context leaves little hope of precise dating.

Beyond introducing poorly dated specimens to the analysis of evolutionary tempo, this study points to a persistent bias common to questions of phyletic gradualism. That bias concerns the need to adopt a detailed serial chronology as a framework for organizing the fossil data. That chronology reifies the morphological progression perceived in the data by gradualists.

Certainly any test of evolutionary tempo requires a chronological framework. I only question the need to study a succession of individuals rather than analyze 
the variation in a sample.

\section{UNIVARIATE ANALYSIS}

The univariate analysis employed in this study proved inadequate to describe the variation present in the sample. The results were contradictory. Three variables indicated the three groups were indistinct. Four variables, including two face and two calvarium metrics, indicated the mid Pleistocene and post Göttweig specimens were similar to each other and distinct from the Würm I sample. Finally, two variables distinguished the mid Pleistocene from the Würm I specimens, while 16 showed the groups were not different.

These results not only cast doubt on previous work based on analysis of single variables, but also analyses conducted on limited portions of the cranium. If subsets of the data contradict one another, then analyses employing measurements from a limited portion of the cranium may by chance produce results inconsistent with total cranial morphology. An analysis of cranial fragments is inadvisable whether the study is univariate or multivariate.

\section{PRINCIPAL COMPONENT ANALYSIS}

In contrast to the univariate analysis, PCA provided a clear picture of morphological variation through time. The three temporal samples were confidently placed in two morphological groups.

Primarily on the basis of facial morphology, component I clearly separated the mid Pleistocene and Würm I samples from the later post 
Göttweig Homo sapiens. The values for all 12 variables that loaded on the first component were uniformly larger in the early groups than in the post Göttweig sample. In part, these results show that facial size is larger in early Homo sapiens than the post Göttweig sample. In addition, mid-facial projection, as measured by the prosthion and ectoconchion radii, is greatest in the two early groups. In sum, results of the PCA quantify observable differences in facial morphology between archaic and anatomically modern Homo sapiens.

The third component similarly reflects observable variation in calvarium form within Homo sapiens. Small values for the vertex radius and frontal subtense as well as parietal chord, subtense, and fraction reflect a low flat calvarium in the two early groups. Higher values for those variables in the post Göttweig group reflects the higher rounded calvarium in modern Homo sapiens.

Naturally, it is satisfying to obtain quantitative results that mirror observable differences in archaic and modern Homo sapiens. The implication of these results, however, extends beyond reifying an informal subspecific division of Homo sapiens. The pattern of morphological variation also reflects the tempo of evolutionary change in Homo over the last $200 \mathrm{KY}$.

As the bivariate plot in Figure 7 shows, the distribution of variation is not continuous. Instead, individuals cluster in two discrete morphological patterns. Furthermore the clusters are not characterized by a random distribution of elements. Individuals are aligned on axes which appear 
approximately parallel in the two clusters.

This absence of a random, shotgun blast distribution in the entire sample or in the individual clusters suggests that morphological variation is patterned. Since the data within clusters are not arrayed in time series, they cannot be tested for random walk (see Bookstein 1987). Nevertheless, the lineal distribution of elements within clusters argues against unpatterned variation.

If the data evince non-random variation, then a determination of evolutionary tempo is possible. As noted above, the data clearly distribute in discrete clusters. There is little doubt of the morphological reality behind these clusters or that they distinguish between the earlier archaic and later anatomically modern forms of Homo sapiens. The cluster analysis of component scores groups the 32 post Göttweig members of my sample apart from the 9 Würm I and mid Pleistocene specimens. No evidence of continuous morphological change appears.

This pattern occurs in contrast to that illustrated in Figure 9. Figure 9 is a bivariate plot of components I and III extracted from a sample composed of the post Göttweig group and 207 recent European males and females measured by W.W. Howells. This distribution of post Göttweig and recent individuals is continuous and suggest microevolutionary adjustment of the anatomically modern morphology.

No indication of continuous microevolutionary change appears in the mid Pleistocene, early Würm, and post Göttweig sample. The data clearly demonstrate stasis. The morphology present in the mid Pleistocene continued 
unchanged through the early Würm until the Göttweig interstadial. At the end of the Göttweig, a modern cranial form suddenly replaced the earlier morphology. As indicated by Figure 9, the modern form has undergone only minor adjustments since the post Göttweig Würm glaciation. 


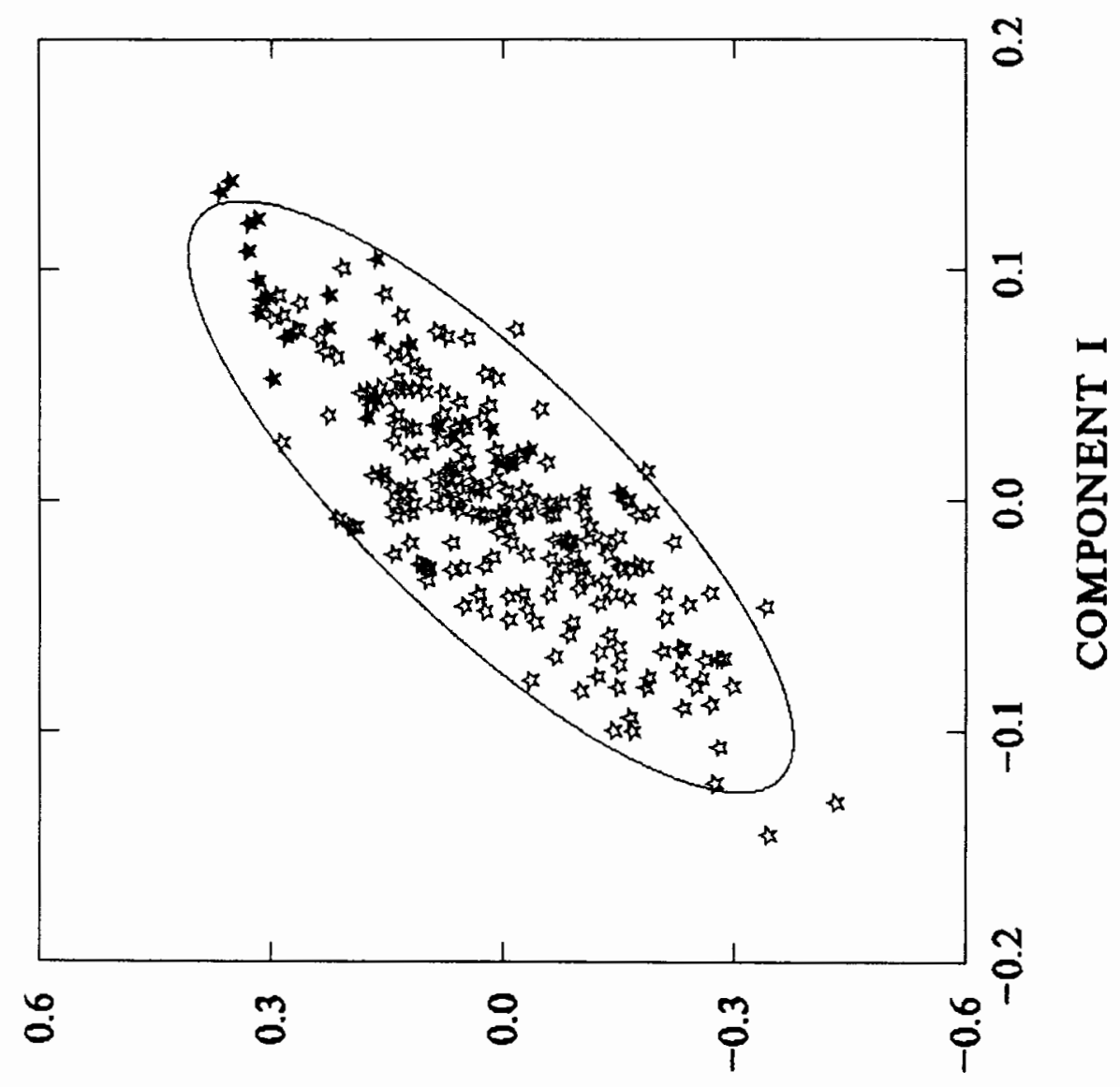

III INGNOdWOS

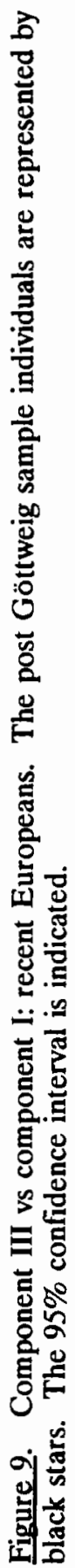




\section{CHAPTER V}

\section{CONCLUSION}

The rediscovery of Mendel's rules of inheritance in the early 1900's stimulated a rapid transformation of the biological sciences. Well before this century was half over the basic structure of the modern evolutionary synthesis was in place. For the next thirty years the synthesis settled into a sort of stability characterized by refinement of those basic structures rather than any substantial change. Suddenly, during the 1970's, the synthesis was shaken to its core. From the periphery of the scientific community the idea of punctuated equilibrium emerged.

Many perceived Eldredge and Gould's concept as a revolutionary attack on the synthesis rather than an evolutionary transformation of the older paradigm. In part, proponents of punctuated equilibrium advocated a new level of testability. In that spirit, many of the old guard undertook defending the synthesis by attempting to discredit every proposed example of stasis. Their attacks are based on the assumption that Punctuated equilibrium is refutable with any example of gradual change. That, however, was not the way Eldredge and Gould presented Punctuated equilibrium. As Padian (1989:75) notes, "Punctuated equilibrium is a probabilistic statement, and the existence of gradual change does not falsify the validity of punctuated equilibrium as a 
concept."

To proceed with our study of evolutionary processes, we must adopt methodologies designed to fairly test evolutionary tempo. This analysis identified a few requirements for a fair test of stasis. Perhaps most importantly, stasis or gradualism describes the presence or absence of change within a population. Gradualism is not proved by a vector of change identified in successional species.

A second issue concerns the object of study. Questions of evolutionary tempo address changes in shape over time. No single dimension describes shape and, therefore, individual measurements removed from the context of anatomical form tell nothing of evolutionary tempo. In addition, it is far too easy to collect only dimensions that support either stasis or gradualism in order to bolster a particular model. Clearly, a study of evolutionary tempo requires a multivariate methodology designed to identify variation in shape within a population.

The objective of evolutionary biology is to generate models that explain the development of variation within and among species and then test the limitations of those models. At present, there are two models of evolutionary change. Our understanding of evolutionary processes is poorly served by the blind defence of one model over the other. Instead, we must attempt to determine the circumstances that lead to either gradual change or stasis. 


\section{REFERENCES CITED}

Anderson T.W. 1963. Asymptotic Theory for Principle Component Analysis. Annals of Mathematical Statistics. 34(1):122-148.

Bookstein F. 1987. Random Walk and the Existence of Evolutionary Rates. Paleobiology 13(4):446-464.

Bookstein F., B. Chernoff R. Elder, J. Humphries, G. Smith \& R. Strauss 1985. Morphometrics in Evolutionary Biology. Philadelphia: The Academy of Natural Sciences of Philadelphia.

Butzer K. 1982. Archaeology as Human Ecology: Method and Theory for a Contextual Approach. Cambridge: Cambridge University Press.

Chinzei K. 1970. The Amud Cave Site and Its Deposits. In The Amud Man and His Cave Site. H Suzuki \& F Takai eds. Pp. 21-52 Tokyo: University of Tokyo Press.

Cook J., C.B. Stringer, A.P. Currant, H.P. Schwarcz, \& A.G. Wintle 1982. A Review of the Chronology of the European Middle Pleistocene Hominid Record. Yearbook Of Physical Anthropology 25:19-25.

Cronin J.E., N.T. Boaz, C.B. Stringer \& Y. Rak 1981. Tempo and Mode in Hominid Evolution. Nature 292:113-122.

Day M.H. 1986. Guide to Fossil Man: A Handbook of Human Paleontology, $4^{\text {th }}$ edition. Chicago: University of Chicago Press.

Eldredge N. \& S.J. Gould 1972. Punctuated Equilibrium: An Alternative to Phyletic Gradualism. In Models in Paleobiology. T.J.M. Schopf, ed. Pp. 82-115. San Francisco: Freeman Cooper.

Feldesman M.R. 1976. The Primate Forelimb: A Morphometric Study of Locomotor Diversity. University of Oregon Anthropological Paper NO. 10

Frayer D.W. 1984. Biological and Cultural Changes in the European Late Pleistocene and Holocene. In The Origins of Modern Humans: A World Survey of the Fossil Evidence. F.H. Smith \& F. Spencer, eds. Pp. 211250. New York: Alan R. Liss. 
Gamble C. 1986. The Paleolithic Settlement of Europe. Cambridge: Cambridge University Press.

Gingerich P.D. 1976. Cranial Anatomy and Evolution of Early Tertiary Plesiadapidae (Mammalia, Primates). Papers on Paleontology No. 15. Ann Arbor: Museum of Paleontology University of Michigan.

Gould S.J. 1966. Allometry and Size in Ontogeny and Phylogeny. Biological Reviews of the Cambridge Philosophical Society. 41:587-640.

1982. Darwinism and the Expansion of Evolutionary Theory. Science 216:380-387.

Gould S.J. \& N. Eldredge 1977. Punctuated Equilibria: The Tempo and Mode of Evolution Reconsidered. Paleobiology 3:115-150.

Howells W.W. 1973. Cranial Variation in Man: A Study by Multivariate Analysis of Patterns of Differences Among Recent Human Populations. Papers of the Peabody Museum of Archaeology and Ethnology 67.

Jolicoeur P. \& J.E. Mosimann 1960. Size and Shape Variation in the Painted Turtle: A Principle Component Analysis. Growth 24(4):339-354.

Levinton J.S. 1982. Estimating Stasis: Can a Null Hypothesis Be Too Null? Paleobiology 8:307

Mann A. \& E. Trinkaus 1973. Neandertal and Neandertal-Like Fossils from the Upper Pleistocene. Yearbook of Physical Anthropology 17:169-193.

Morrison D.F. 1967. Multivariate Statistical Methods. New York: McGrawHill Book Co.

Mosimann J.E. \& F.C. James 1979. New Statistical Methods for Allometry with Applications to Florida Redwinged Blackbirds. Evolution 33:444459.

Murrill R.V. 1981. Petralona Man: A Descriptive and Comparative Study, with New Important Information on Rhodesian Man. Springfield: Charles C Thomas.

Oxnard C. 1973. Form and Pattern in Human Evolution: Some Mathematical, Physical, and Engineering Approaches. Chicago: The University of Chicago Press.

1984. The Order of Man: A biomathematical Anatomy of the Primates. New Haven: Yale University Press. 
Padian K. 1989. The Whole Real Guts of Evolution. Paleobiology 15: 73-78.

Pimentel R.A. 1979. Morphometrics: The Multivariate Analysis of Biological Data. Dubuque: Kendall/Hunt Publishing Co.

Rightmire G.P. 1981. Patterns in the Evolution of Homo erectus. Paleobiology 7: $241-247$.

1982. Reply to Levinton. Paleobiology 8:307.

1985. The Tempo of Change in the Evolution of Mid-Pleistocene Homo. In Ancestors: The Hard Evidence. E. Delson, ed. New York: Alan R. Liss.

1986. Stasis in Homo erectus defended. Paleobiology 12:324.

Smith R.J. 1980. Rethinking Allometry. Journal of Theoretical Biology. 87:97111.

Stanley, S.M. 1979. Macroevolution, Patterns and Process. San Francisco: W.H. Freeman.

Stringer C.B., J.J. Hublin, \& B. Vandermeersch 1984. The Origin of Anatomically Modern Humans in Western Europe. In The Origins of Modern Humans: A World Survey of the Fossil Evidence. F.H. Smith \& F. Spencer, eds. Pp. 51-135. New York: Alan R. Liss.

Valladas S.H., J.L. Reyss, J.L. Joron, G. Valladas, O. Bar-Yosef \& B. Vandermeersch 1988. Thermoluminescence Dating of Mousterian "Proto-Cromagnon" remains from Israel and the Origin of Modern Man. Nature 331:614-616.

Vrba E.S. 1982. Biostratigraphy and Chronology, Based Particularly on Bovidae, of southern hominid-associated assemblages: Makapansgat, Sterkfontein, Taung, Kromdraai, Swartkrans; also Elandsfontein (Saldanha), Broken Hill (now Kabwe) and Cave of Hearths. Cong. Int. Paleont. hum. I. Nice Pp 707-752.

Wolpoff M.H. 1980. Paleoanthropology. New York: Alfred A Knopf. 1984. Evolution in Homo erectus: The Question of Stasis. Paleobiology 10:389-406.

1986. Stasis in the interpretation of Evolution in Homo erectus: a Reply to Rightmire. Paleobiology 12:325-328. 
Wolpoff M.H., Wu X.Z. \& A.G. Thorne 1984. Modern Homo sapiens Origins: A General Theory of Hominid Evolution Involving the Fossil Evidence From East Asia. In The Origins of Modern Humans: A World Survey of the Fossil Evidence. F.H. Smith \& F. Spencer, eds. Pp. 411-483. New York: Alan R. Liss.

Zar J.H. 1984. Biostatistical Analysis, $2^{\text {nd }}$ edition. Englewood Cliffs: Prentice-Hall Inc. 